\title{
COMPOSICIÓN DE LOS HOGARES Y NIVELES DE GASTOS EN BIENES Y SERVICIOS BÁSICOS EN EL DEPARTAMENTO DEL CAUCA, COLOMBIA*
}

\author{
Recibido: 12 de diciembre de 2014 • Aprobado: 21 de noviembre de 2015 \\ Andrés Mauricio Gómez Sánchez ${ }^{*}$ \\ Claudia Liceth Fajardo Hoyos ${ }^{* * *}$ \\ Juliana Isabel Sarmiento Castillo***
}

\section{RESUMEN}

Éste documento tiene como objetivo caracterizar los hogares rurales y urbanos del departamento del Cauca, Colombia y clasificarlos según la tipología y el ciclo de vida del hogar, para establecer su relación con los niveles de gasto mínimo en bienes básicos, es decir, con los que definen los umbrales críticos de pobreza. Para tal efecto, se utiliza la Encuesta de Calidad de Vida de 2011 y se estiman modelos de análisis de varianza multifactoriales. Los resultados muestran, entre otros, que el tipo de hogar más frecuente, tanto en el área rural como la urbana, es el nuclear con hijos y los gastos mínimos básicos, en general, son en alimentos, vivienda y salud. Los rubros de educación y transporte presentan niveles más altos de consumo en los hogares urbanos que en los rurales.

\section{PALABRAS CLAVE}

Modelos de ciclo de vida, necesidades básicas, estándares de vida, demanda regional de los hogares, consumo de los hogares.

\section{CLASIFICACIÓN JEL}

D12, D91, 131, I32, R21

\section{CONTENIDO}

Introducción; 1. Referentes conceptuales, teóricos y estudios aplicados; 2. Caracterización y clasificación de los hogares en el departamento del Cauca; 3. Modelo econométrico; 4. Conclusiones; Bibliografía.

Este documento es producto de la investigación denominada "Elaboración de Mapas y Líneas de Pobreza para la Ciudad de Popayán" financiado por la Universidad del Cauca.

** Economista, Universidad del Valle, Cali, Colombia. Especialista, Gerencia de Proyectos, Universidad del Cauca, Popayán, Colombia. Magíster en Economía Aplicada, Universidad del Valle, Cali, Colombia. Docente del Departamento de Economía, Universidad del Cauca, Popayán, Colombia. Miembro del Grupo de Investigación Entropía, Universidad del Cauca, Popayán, Colombia. Dirección: Calle 5 No. 4-70, Universidad del Cauca, Popayán, Colombia. Correo electrónico: amgomez@unicauca.edu.co.

*. Economista, Universidad del Valle, Cali, Colombia. Magíster en Economía Aplicada, Universidad del Valle, Cali, Colombia. Docente del Departamento de Economía, Universidad del Cauca, Popayán, Colombia. Miembro del Grupo de Investigación Entropía, Universidad del Cauca, Popayán, Colombia. Dirección: Calle 5 No. 4-70, Universidad del Cauca, Popayán, Colombia. Correo electrónico: cfajardo@unicauca.edu.co.

**** Economista, Universidad del Cauca, Popayán, Colombia. Especialista en Finanzas, Universidad del Valle, Cali, Colombia. Candidata a PhD. en Ciencias Ambientales, Universidad del Cauca, Popayán, Colombia. Docente del Departamento de Economía, Universidad del Cauca, Popayán, Colombia. Miembro del Grupo de Investigación Entropía, Universidad del Cauca, Popayán, Colombia. Dirección: Calle 5 No. 4-70, Universidad del Cauca, Popayán, Colombia. Correo electrónico: jisarmiento@unicauca.edu.co. 


\section{HOUSEHOLD COMPOSITION AND EXPENDITURE LEVELS ON BASIC GOODS AND SERVICES IN THE DEPARTMENT OF CAUCA, COLOMBIA}

\section{ABSTRACT}

The main objective of this paper is to describe the rural and urban households of the Cauca department in Colombia. The idea is to classify the households according to their typology and household life cycle in order to establish their relation with the minimum levels of expenditure on basic goods, this means with the ones that define the critical poverty thresholds. For this end, the 2011 Quality of Life survey is used as well as multifactorial variance analysis. The results show that the most common type of household for both rural and urban areas is the nuclear type of household with children, showing usually a minimal basic expenditure on food, housing and health. Education and transportation present higher consumption levels at urban households.

\section{KEY WORDS}

Life cycle models, basic needs, life standards, household regional demand, household consumption.

\section{JEL CLASSIFICATION}

D12, D91, I31, 132, R21

\section{CONTENT}

Introduction; 1. Theoretical, conceptual and applied studies referents; 2 . Household characterization and classification in the Cauca department; 3. Econometric model; 4. Conclusions; Bibliography.

\section{COMPOSIÇÃO DE LARES E NIVEIS DE GASTOS EM BENS E SERVIÇOS BÁSICOS NO DEPARTAMENTO DO CAUCA, CÔLOMBIA}

\section{RESUMO}

Este documento tem como objetivo caracterizar os lares rurais e urbanos do departamento do Cauca, Colômbia e classifica-los segundo a tipologia e o ciclo de vida do lar, para estabelecer sua relação com os níveis de gasto mínimo em bens básicos, ou seja, com os que definem os umbrais críticos de pobreza. Para tal efeito, se utiliza a Enquete de Qualidade de Vida de 2011 e se estimam modelos de análise de variância multifatoriais. Os resultados mostram, entre outros, que o tipo de lar mais frequente, tanto na área rural como na urbana, é o nuclear com filhos e os gastos mínimos básicos, em geral, são em alimentos, moradia e saúde. Os setores de educação e transporte apresentam níveis mais altos de consumo nos lares urbanos do que nos rurais.

\section{PALAVRAS CHAVE}

Modelos de ciclo de vida, necessidades básicas, padrões de vida, demanda regional dos lares, consumo dos lares.

\section{CLASSIFICAÇÃO JEL}
D12, D91, I31, I32, R21

\section{CONTEÚDO}

Introdução; 1. Referentes conceituais, teóricos e estudos aplicados; 2. Caracterização e classificação dos lares no departamento do Cauca; 3. Modelo econométrico; 4. Conclusões; Bibliografia. 


\section{INTRODUCCIÓN}

Existen diferentes formas de clasificar los hogares, entre ellas la tipología clásica y la tipología del ciclo de vida. Ambas parten de la composición de los miembros y toman como referencia el hogar nuclear biparental, es decir, aquel que cuenta con ambos padres e hijos. Según Ramírez y Muñoz $(2004$, p. 8) en la primera clasificación existen doce categorías que obedecen al número de miembros del hogar y su relación con el jefe, en la segunda que corresponde a la tipología del ciclo de vida, se cuenta con cinco posibles clasificaciones, donde se considera que las etapas de la vida por las que pasan los hogares definen su taxonomía, es así como se encuentran desde hogares conformados por parejas jóvenes sin hijos, hasta hogares de parejas mayores que tuvieron hijos pero ya se han ido. Vale la pena aclarar que de acuerdo a los contextos, datos disponibles e intereses investigativos, el número de clasificaciones pueden sufrir algún tipo de variación.

Estudiar la tipología de los hogares se hace necesario por varias razones. En primera instancia, Barahona (2006, p. 19), encuentra que la distribución de la pobreza no es aleatoria sino que está arraigada a ciertas tipificaciones de hogares, por tanto una forma de combatirla es conocer cuáles son los hogares donde tiene prevalencia y cuál es su estructura. Otra razón para estudiar la tipología de los hogares es que permite ahondar en el conocimiento de la dependencia demográfica de los hogares, es decir, de la relación existente entre las personas en edad no productiva (niños y ancianos) y los adultos productivos.

Un factor ligado a la clasificación de los hogares tiene que ver con los niveles de gasto de los mismos en bienes y servicios básicos. Las diferentes etapas del ciclo de vida y los diferentes tipos de hogares impiden que se puedan mantener los mismos patrones de consumo y las mismas cantidades en el tiempo. En efecto, si una familia se clasifica como nuclear biparental debe gastar entre otras cosas en educación, salud y recreación, pero otra donde ya los hijos de han ido del hogar, debe gastar mucho más en salud, y la educación o la recreación pasarían a un segundo plano. Esta relación entre tipología de hogares y niveles de gasto es también importante ya que permite identificar la brecha que existe entre las necesidades de consumo propias del tipo de hogar y los gastos que realizan.

Existen pocos estudios en Colombia sobre la relación entre gastos del hogar y su tipología, y los pocos encontrados se han realizado para las ciudades grandes, pero para las ciudades pequeñas o intermedias son inexistentes, lo que ameritaría un mayor número de estudios e investigaciones en esta línea. El Cauca es uno de los departamentos que carece de este tipo de investigaciones, el mismo presenta uno de los mayores niveles de pobreza del país, con una incidencia a 2012 del 62,1\% 
y del 34\% en extrema pobreza y un índice de concentración de Gini igual a 0,56, según el DANE (2012). En adición, su capital presentaba a 2012 uno de los mayores niveles de desempleo del país, 19.1\% en promedio en el último lustro de acuerdo al ORMET (2013), esto sin ahondar en los problemas sociales como el conflicto armado.

En este orden de ideas, este artículo tiene por objetivo presentar evidencias sobre la composición y los niveles de gasto mínimo de los hogares tanto rurales como urbanos del departamento del Cauca para el periodo 2011, como una forma de contribuir al análisis de la dinámica social y económica de esta región del país. Para propósitos del análisis, se clasifican los gastos de forma geográfica, es decir en zona rural o urbana, debido a que las ciudades presentan otro tipo de dinámicas en los mercados frente a las zonas rurales y, por tanto, se presupone que los niveles de gasto deben ser disímiles para las diferentes tipologías y ciclos de vida.

Para tal fin el documento se divide en cuatro secciones, sin incluir la introducción. En el primer apartado se realiza una revisión de la taxonomía de los hogares acompañados de referencias para algunos estudios aplicados recientes en este campo. Luego se explica la obtención y tratamiento de la información y se efectúan algunos análisis descriptivos de la misma. En la tercera parte se construyen y se estiman los modelos econométricos que capturan la relación tipología-gasto de los hogares y para finalizar se realizan algunas conclusiones y recomendaciones.

\section{REFERENTES CONCEPTUALES, TEÓRICOS Y ESTUDIOS APLICADOS}

\subsection{Conceptualización}

La palabra hogar y familia son conceptos que se utilizan de manera indistinta para referirse a un espacio o a un grupo de personas donde se nace, se crece, se aprende y se crean lazos de afecto. Sin embargo, estas son definiciones diferentes. La familia está definida desde muchos espacios como: un grupo de personas unidas por vínculos de parentesco, ya sea consanguíneo, por matrimonio o adopción que viven juntos por un período indefinido de tiempo (Barahona, 2006). Pero esta definición no alcanza a abarcar la naturaleza peculiar de las familias. El ICBF (2012, p. 15) reconoce la dificultad de aventurarse en la definición de hogar y de familia:

En términos muy amplios y con fines estadísticos, suele identificarse como hogar al grupo humano que comparte techo y presupuesto de alimentos. Resulta sin embargo mucho más complejo, intentar una definición de familia, pues esta define a un grupo humano, por factores diferentes a los físicos (presupuesto y techo). La Familia es una estructura en permanente cambio, afectada por el contexto social, económico, político, cultural del país, y a su interior por sus proyectos de vida y los planes individuales, 
Composición de los hogares y niveles de gastos en bienes y servicios básicos en el Departamento del Cauca, Colombia

también cambiantes. Unos y otros factores interactúan de forma tal que cuando se presentan situaciones de crisis externas (económicas, sociales, climáticas, políticas, etc.), sus miembros promueven modificaciones a su interior, generando cambios en sus roles y conformando estrategias que les permita enfrentarlas.

El DANE (2011, p. 10) por su parte define hogar como: "una persona o grupo de personas, parientes o no, que ocupan la totalidad o parte de una vivienda; atienden necesidades básicas con cargo a un presupuesto común y generalmente comparten las comidas". La familia es una realidad que se transforma en el tiempo, en razón a los cambios sociales, económicos y culturales. Su carácter cambiante hace que para entenderla sea necesario observarla desde diferentes disciplinas pues la dinámica de tales cambios ha involucrado nuevas ópticas, tales como la económica, la filosófica, y la política.

Los cambios de diversa índole en la sociedad colombiana hacen que convivan tipologías familiares tradicionales y modernas fundamentadas en el parentesco y consanguinidad, con tipologías cuya conformación está determinada por los cambios recientes, marcados por el énfasis del reconocimiento a la diversidad y motivada por otros factores diferentes a los habituales. En este sentido, Echeverri (2004, p. 7) manifiesta que muchos de los cambios recientes registrados en los diferentes arreglos que hacen las personas y que dan lugar a la conformación de familias, comienzan a ser más visibles en el espacio de lo social, lo político y lo jurídico.

De otra parte, para efectos de su cuantificación e identificación, más que de familias se puede hablar de hogares. Existe cierto consenso en reconocer que por lo general el concepto de hogar se aplica a un grupo humano que vive bajo el mismo techo, comparte presupuesto y alimentos. Estas características permiten identificar a estos grupos humanos con relación a variables físicas como por ejemplo la vivienda, y variables económicas como el gasto privado. La forma como se aborde el estudio de la tipología de los hogares en buena medida depende de los objetivos e intereses de los investigadores, es así como existen diferentes clasificaciones cuyo criterio va desde la forma cómo se relacionan los miembros, pasando por su parentesco, o desde las formas de ejercer autoridad hasta el periodo del ciclo de vida en el que se encuentre el hogar.

\subsubsection{La tipología clásica}

La relación de parentesco parte de algunas premisas básicas como los vínculos de tipo biológico y no biológico (afectivos, jurídicos, etc.) que tienen las personas, así como su condición de residentes habituales. En la siguiente tabla se relaciona las diferentes tipologías de los hogares de acuerdo a su parentesco. 
Andrés Mauricio Gómez Sánchez - Claudia Liceth Fajardo Hoyos - Juliana Isabel Sarmiento Castillo

Tabla 1. Tipología clásica del hogar según parentesco

\begin{tabular}{|l|l|l|}
\hline \multicolumn{1}{|c|}{ Tipo } & \multicolumn{1}{|c|}{ Subtipo } & \multicolumn{1}{c|}{ Composición } \\
\hline \multirow{3}{*}{ Nuclear } & Nuclear sin hijos & Jefe y cónyuge \\
\cline { 2 - 3 } & Nuclear con hijos & Jefe, cónyuge e hijos. \\
\hline \multirow{4}{*}{ Nuclear Monoparental } & & Jefe y su hijo(s). \\
\hline \multirow{4}{*}{ Extensos } & Extensos sin hijos & Jefe, cónyuge y parientes \\
\cline { 2 - 3 } & Extenso con hijos & Jefe, cónyuge, hijos y parientes. \\
\cline { 2 - 3 } & Extenso monoparental & Jefe, hijos y parientes \\
\cline { 2 - 3 } & Extenso sin núcleo & Jefe y parientes \\
\hline \multirow{3}{*}{ Compuestos } & Compuesto nuclear & jefe, cónyuge, hijos y no parientes \\
\cline { 2 - 3 } & Compuesto extenso & Jefe, cónyuge, hijos, parientes y no parientes \\
\cline { 2 - 3 } & Compuesto sin núcleo & Jefe, parientes y no parientes \\
\hline Unipersonal & & Jefe \\
\hline No familiar & & Jefe y no parientes \\
\hline
\end{tabular}

Fuente: Ramírez y Muñoz (2004, p. 8)

La presente investigación clasificará a los hogares caucanos según la tipología clásica basada en el parentesco, se siguen algunos estudios como el del ICBF (2012, p. 23) que excluyen de ella a personas residentes no habituales y a las personas empleadas del servicio doméstico cuando estas no son residentes habituales, o incluso si lo son, los vínculos con el resto de la familia son de parentesco no biológico.

\subsubsection{Tipología según el ciclo de vida del hogar}

Los ciclos de vida segmentan tipologías de hogares basados en las distintas etapas que marcan la vida de una persona, y que a su vez determinan una diferente estructura del hogar. La tipología según el ciclo de vida familiar tiene como variables de referencia la edad del hijo mayor, la edad del hijo menor y la edad de la madre.

Tabla 2. Ciclo de vida del hogar

\begin{tabular}{|l|l|}
\hline \multicolumn{1}{|c|}{ Tipo } & \multicolumn{1}{c|}{ Composición } \\
\hline Pareja joven sin hijos & $\begin{array}{l}\text { Parejas que no tienen hijos y la mujer tiene una edad menor } \\
\text { a } 40 \text { años. }\end{array}$ \\
\hline Ciclo de inicio de la familia & Parejas que únicamente tienen hijos menores de seis años. \\
\hline Ciclo de expansión o crecimiento & Familias en donde sus hijos menores tienen hasta doce años. \\
\hline Ciclo de consolidación y salida & Familias en donde sus hijos menores tiene trece años o más. \\
\hline Pareja mayor sin hijos (nido vacío) & Parejas que no tienen hijos y la mujer tiene 40 años o más. \\
\hline
\end{tabular}

Fuente: Ramírez y Muñoz (2004, p. 8) 
Composición de los hogares y niveles de gastos en bienes y servicios básicos en el Departamento del Cauca, Colombia

La anterior clasificación es muy simple ya que solo incluye los hogares de parejas con o sin hijos, y deja por fuera los diversos estilos de vida y acuerdos familiares que hoy en día son comunes en la sociedad, tales como hogares con madres o padres solteros, hogares conformados por personas del mismo sexo, entre otros.

\section{La teoría del ciclo de vida y los gastos de los hogares}

Las decisiones de consumo y por ende de ahorro de las unidades familiares en este caso los hogares, se consideran como un proceso de elección que intenta optimizar el resultado de enfrentar las preferencias de los sujetos con los posibilidades o restricciones de presupuesto. Por tanto, las decisiones tomadas por dichas unidades son racionales. Estas vienen dadas por el conjunto de recursos a disposición de las familias en el pasado, el presente y futuro. En este orden de consideraciones, Argandoña (1994, p. 5) encuentra que las preferencias a su vez reflejan factores subjetivos, lo que se suele llamar gustos así como otros de carácter objetivo, como el tamaño de la familia, su estructura de edades, su actitud hacia el riesgo entre otros.

Es así como el momento vital de cada hogar entre otras características puede determinar las decisiones de gasto de los mismos. La teoría del ciclo vital cuyo origen se relaciona con los aportes de Modigliani y Brumberg (1954) y de Ando y Modigliani (1963), plantea que el individuo maximiza la utilidad derivada de su consumo a lo largo de toda su vida, sujeta a una restricción presupuestaria que está formada por todos los recursos de los que puede disponer también a lo largo de esta.

El ciclo de vida muestra tres momentos en la vida de los individuos, en el primero la persona no percibe ingresos, después trabaja y por último se jubila. Según Modigliani (1986, p. 300) ésta teoría reconoce

La vida limitada de la unidad familiar, así que la Teoría del Ciclo Vital (TCV) se pudo concentrar en aquellas variaciones sistémicas en el ingreso y en las 'necesidades' que ocurren durante el ciclo de vida como resultado de madurar y retirarse, y los cambios del tamaño de la familia. Además, la TCV se encontraba en condiciones de tomar en cuenta los legados y los motivos de los legados.

Moscoso (2008, p. 5) plantea que ésta teoría se basa en un modelo de optimización intertemporal que busca predecir el comportamiento de la unidad de gasto a lo largo de su vida, así la unidad debe planificar su consumo y ahorro necesario de tal manera que tenga estabilidad en el consumo, los años que no tenga ingresos laborales.

La hipótesis sencilla del ciclo vital se ha visto confirmada sobre todo en los versiones más complejas, que incluyen restricciones a la liquidez de la riqueza, 
mercados de capitales no perfectos, transferencia entre generaciones, seguridad social, etc., han sido objeto de numerosas contrastaciones que por lo general resultan favorables a la hipótesis. Aunque Argandoña (1994, p. 11) afirma que existen algunos problemas en la estimación de diferentes versiones del modelo.

Vale la pena aclarar que el análisis de los gastos mínimos de los hogares se realizará teniendo en cuenta tanto la tipología clásica como la del ciclo de vida, con el fin de poder comparar dichos gastos a la luz de ambas clasificaciones, haciendo énfasis en que el ciclo de vida deja de lado otros tipos de hogares cuya composición no cabe dentro de su definición, mientras que en la tipología clásica estos si puedes ser incluidos.

\subsection{Estudios aplicados}

El estudio del consumo en macroeconomía está muy ligado al estudio del ahorro, es por esta razón que teorías como la del ciclo vital tiene aplicaciones tanto en la explicación del consumo como del ahorro. Los primeros contrastes de la teoría del ciclo vital se deben a los propios autores, Modigliani y Brumberg (1954) y Ando y Modigliani (1957), con datos de corte transversal y Ando y Modigliani (1963) con series temporales.

En cuanto a la relación del ciclo de vida del hogar con los gastos de los hogares por grupos son pocos los trabajos encontrados que exploran de manera directa esta relación. Son más los ejercicios encaminados a relacionar el ciclo de vida del hogar con el ahorro que con los gastos, aunque estás dos variables estén muy relacionadas. Un ejemplo de lo anterior es el estudio de Melo, Zárate y Téllez (2006) para Colombia. Ellos presentan un análisis del comportamiento del ahorro a partir de la hipótesis del ciclo de vida, utilizado los perfiles de ahorro por año de nacimiento del jefe del hogar. Los resultados muestran que tanto el ingreso como el consumo registran un comportamiento de U invertida, sugiriendo que para el caso colombiano no hay evidencia de que se cumpla la hipótesis del ciclo de vida.

Camacho y Hernández (2006) estudian la relación del ciclo de vida de los hogares y el consumo de servicio en España, este trabajo aborda la influencia del ciclo vital familiar sobre las pautas de consumo de servicios y permite detectar la significativa heterogeneidad en las pautas de consumo familiar de servicios según la composición del hogar, la edad del principal aportante y el nivel de ingresos de la familia. Pero no hay desde esta perspectiva una relación con la tipología del hogar y todos los gastos, sino solo con los gastos en servicios.

De otro lado, son múltiples los estudios frente a la composición de los hogares en diferentes países del mundo y en diferentes momentos del tiempo, pero no 
relacionan dicha estructura con los patrones de gasto. Estos estudios muestran que para Latinoamérica en general se ha incrementado la jefatura femenina y ha disminuido el tamaño del hogar. Velásquez (2010) encuentra que para Colombia el aumento de hogares con mujeres jefas se observa en todo el país, pero se presentan evoluciones diferentes para las zonas de cabecera y el resto. Así mismo plantea que pobreza-vulnerabilidad y jefatura femenina están muy asociadas ya que los hogares con jefaturas femeninas tienden a ser más pobres que los encabezados por hombres en las mismas condiciones de subempleo e informalidad.

Para Colombia, el estudio de Ramírez y Muñoz (2004) muestra que el hogar promedio en Soacha está conformado por jefes de hogar que, en promedio, tienen 43 años, los parejas 38 y los hijos alrededor de 13; en todos estos grupos la edad promedio aumentó al menos dos años desde 1993. De los jefes, 28\% son mujeres, proporción que es dos puntos superior a la de diez años atrás. El tamaño del hogar (4.1 personas) y el número de hijos (1.9) han permanecido casi constantes durante los últimos diez años.

Es así como partiendo de estos estudios sobre las tipologías de los hogares, o sobre el ciclo de vida y el ahorro de los hogares, o sobre un tipo determinado de gasto con la composición del hogar, en este artículo se relacionan las tipologías de los hogares con la teoría del ciclo de vida y los decisiones tanto de consumo como de ahorro.

\section{CARACTERIZACIÓN Y CLASIFICACIÓN DE LOS HOGARES EN EL DEPARTAMENTO DEL CAUCA}

En consideración a lo ya mencionado, ésta sección tiene como objetivo dar a conocer los resultados del análisis de la tipología y el ciclo de vida de los hogares caucanos, partiendo de la definición del DANE (2006, p. 8) antes enunciada. Además los microdatos fueron obtenidos a partir de la Encuesta de Calidad de Vida (ECV) del año 2011, resaltando que solo para este año la información capturada fue representativa de manera estadística para el departamento del Cauca, mientras que la disponible para años más recientes solo lo fueron para la región pacífica, esto permite hacer inferencia estadística con una confiabilidad del 95\%. De otra manera, la utilización de las ECV 2012 y 2013, mostrarían resultados poco confiables.

1 Las ECV del 2012 y 2013, tienen representatividad estadística para el Pacífico Colombiano (Chocó, Cauca y Nariño) como un todo, y el Valle del Cauca se toma aparte. Cualquier inferencia estadística o econométrica para el departamento analizado incurrirá en el problema de sesgo se selección muestral. Para mayor información sobre la representatividad, véase DANE (2014). 


\subsection{Caracterización de los hogares}

Para clasificar los hogares caucanos se adoptó una sencilla categorización del ciclo de vida, no obstante se reconoce que con el advenimiento de un gran número y diversos estilos de vida y acuerdos familiares, el Ciclo de Vida Familiar tradicional ha perdido su capacidad para representar en toda su variedad las fases por las que transitan los estilos de vida y los diversos tipos de familia. El departamento del Cauca está conformado por 42 municipios y según proyecciones del DANE (2011) tiene un total de 1,330,756 habitantes, de los cuales casi el 39\% se encuentran ubicados en la zona urbana y el 61\% restante en la zona rural. Aunque la ECV de 2011, indica que del total de hogares caucanos encuestados (2,290 hogares), el 50.17\% (1,149 hogares) pertenecen a la zona rural y el restante $49.82 \%$ (1,141 hogares) a la zona urbana, si se analizan los datos por persona, con un total de 8,323 personas encuestadas, 4,472 de ellas (54\%) se encuentran en el área rural y 3,851(46\%) en el área urbana, lo cual va en la misma línea de los datos censales del departamento del Cauca.

Tabla 3. Número de personas y porcentaje por hogar, rural y urbano

\begin{tabular}{|l|c|c|c|c|}
\hline & No. personas & Porcentaje Población & $\begin{array}{c}\text { Promedio personas } \\
\text { por hogar }\end{array}$ & $\begin{array}{c}\text { Número máximo personas } \\
\text { por hogar }\end{array}$ \\
\hline Rural & 4472 & $54 \%$ & 3,89 & 14 \\
\hline Urbano & 3851 & $46 \%$ & 3,37 & 12 \\
\hline
\end{tabular}

Fuente: elaboración propia con información de la ECV - DANE (2011)

Ésta población pertenece a hogares que tienen en promedio 3.9 personas para el área rural y 3.4 personas para el área urbana. De acuerdo a Fresneda (2007, p. 22), uno de los indicadores simples de pobreza es el número de hogares en hacinamiento crítico, es decir, aquellos hogares en cuya vivienda la relación personas por cuarto es superior a tres, es así como la EVC 2011 revela que el hogar caucano más grande en el área urbana estaba integrado por 12 personas y el más numeroso en el área rural por 14 miembros, lo cual refleja las condiciones de extrema pobreza que se presentan en el Cauca. Si comparamos ésta información con los hallazgos nacionales, se encuentra que el número de personas por hogar ha disminuido con los años, en el último quinquenio aumentan los hogares con 1, 2, 3 y 4 personas, en tanto que disminuyen los de 5 y más. Según Profamilia (2010, p. 36) el tamaño del hogar disminuye de 4.1 a 3.8 personas por hogar, reducción que ocurrió tanto en la zona urbana como en la rural, si bien fue más importante en esta última, pasando de 4.4 a 3.9 . 
Composición de los hogares y niveles de gastos en bienes y servicios básicos en el Departamento del Cauca, Colombia

Gráfico 1. Número de Hogares por vivienda, ECV 2011

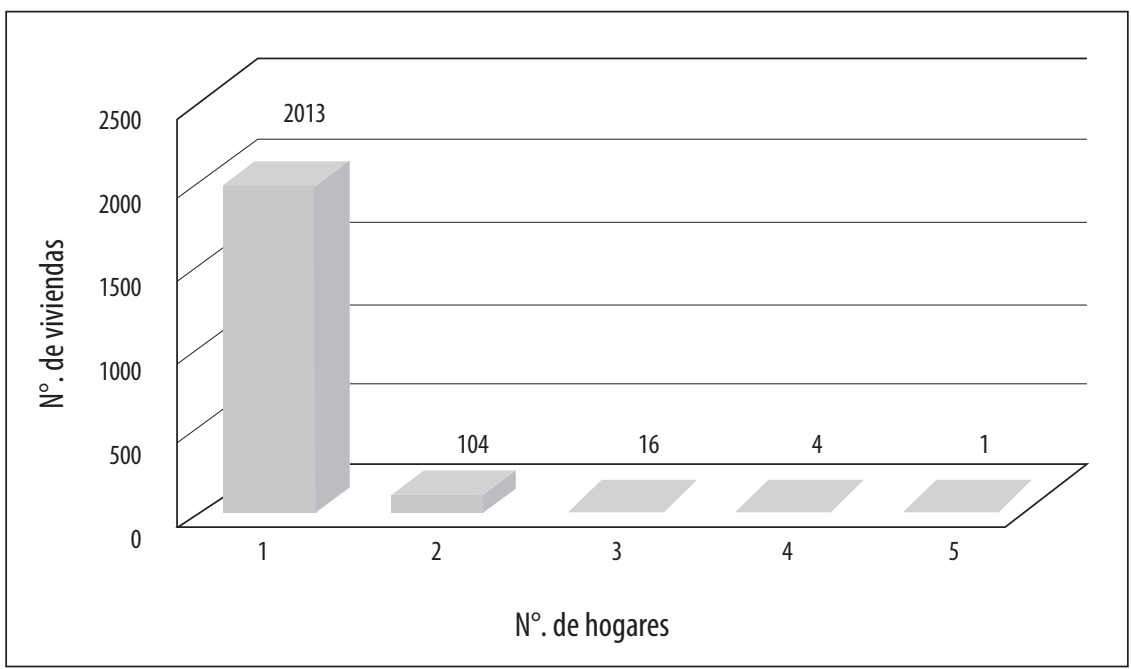

Fuente: Elaboración propia con información de la ECV - DANE (2011)

Los hogares caucanos se alojan en un total de 2,138 viviendas. El gráfico 1 muestra que en su gran mayoría, el 94\% de las viviendas, son habitadas por un solo hogar; el 5\% están ocupadas por dos hogares; y el 1\% tres hogares o más. Aunque la vivienda es un bien que permite satisfacer las necesidades habitacionales del hogar, no es el único rol que ella juega en las estrategias de vida del hogar. Así la condición de propietario permite que el activo vivienda asuma funciones muy diferentes, según Fuentes (1999, p. 4) quien plantea que ésta "puede también ser movilizada para actividades productivas dentro de los confines del hogar, permite desarrollar estrategias de incorporación y absorción de allegados y otras familias, y puede ser orientada a generar recursos financieros cuando es usada ya sea como fuente de ingresos mediante el arriendo, total o parcial, como garantía de crédito para la familia, como recurso de garantía a terceros". Por tanto, en la condición de no propietario, la vivienda reduce las potencialidades de múltiple uso, aunque parte de las estrategias antes señaladas también son posibles.

\subsubsection{Jefatura de hogares}

Otro rasgo general de los hogares caucanos importante de resaltar es el incremento en la jefatura femenina. Según Arriagada (2000, p. 14) "en las áreas urbanas de América latina, la estructura familiar se caracteriza por el progresivo aumento de importancia de los hogares de jefatura femenina, situación que ha sido impulsada por una serie de factores sociales $y$ demográficos. Los hogares de jefatura femenina corresponden principalmente al caso de hogares incompletos, con ausencia del cónyuge o pareja". No obstante, otro determinante asociado 
al incremento de hogares en cabeza de mujeres, se considera al denominado proceso de "feminización de la pobreza", lo cual justifica realizar este tipo de especificaciones.

Gráfico 2. Porcentaje de hombres y mujeres jefes de hogar, rural y urbano

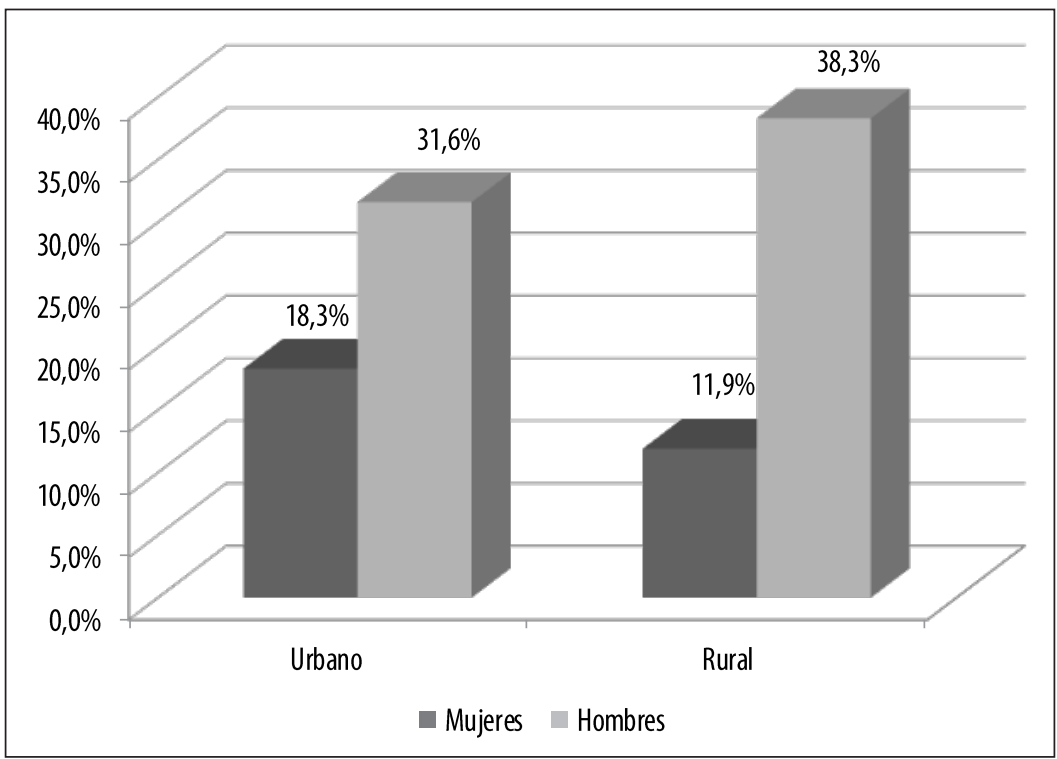

Fuente: elaboración propia con información de la ECV - DANE (2011)

En Colombia, según Velásquez (2010, p. 3), esto se ha reflejado con el crecimiento de un 5.5\% del fenómeno de jefatura femenina en los hogares a lo largo del periodo intercensal 1993-2005. Esto se podría explicar ya sea por disolución de parejas o por el creciente número de madres solteras o desde el embarazo en adolescentes registrado sobre todo en los países subdesarrollados, lo que las lleva a buscar ingresos para solventar los gastos de las personas a su cargo. En el Cauca ha ocurrido algo similar al promedio nacional, según información censal del año 2005, la jefatura femenina era alrededor del 27\%, al parecer solo en 6 años la participación de las mujeres ha aumentado al 30\%, mientras que el 70\% restante está en cabeza de los hombres, es decir que la participación masculina ha disminuido 3 puntos porcentuales. Sumado a ello, la participación de la jefatura femenina es mayor en la ciudad que en el área rural por 6 puntos porcentuales. A pesar de esto, el porcentaje de la jefatura masculina todavía representa más del doble de su similar femenina, lo que significa que en el Cauca aún predomina la jefatura liderada por un hombre.

Lo anterior se relaciona en parte con la mayor participación en el mercado laboral de las mujeres en la zona urbana. La integración de las mujeres al mercado laboral se manifiesta como una tendencia de largo plazo y de carácter estructural. Ellas aportan ingresos a la familia para cubrir las necesidades básicas y un nivel 
adecuado de consumo. Estudios de la $\operatorname{CEPAL}(2013$, p. 16) reconocen que los patrones de comportamiento de las generaciones más jóvenes, con mayores niveles de escolarización y nuevos modelos e identidades laborales reflejan que los proyectos laborales de las mujeres son cada vez más centrales en los vidas, por lo que su participación en el trabajo continuará creciendo.

Gráfico 3. Edad promedio de mujeres y hombres jefes, rural y urbano

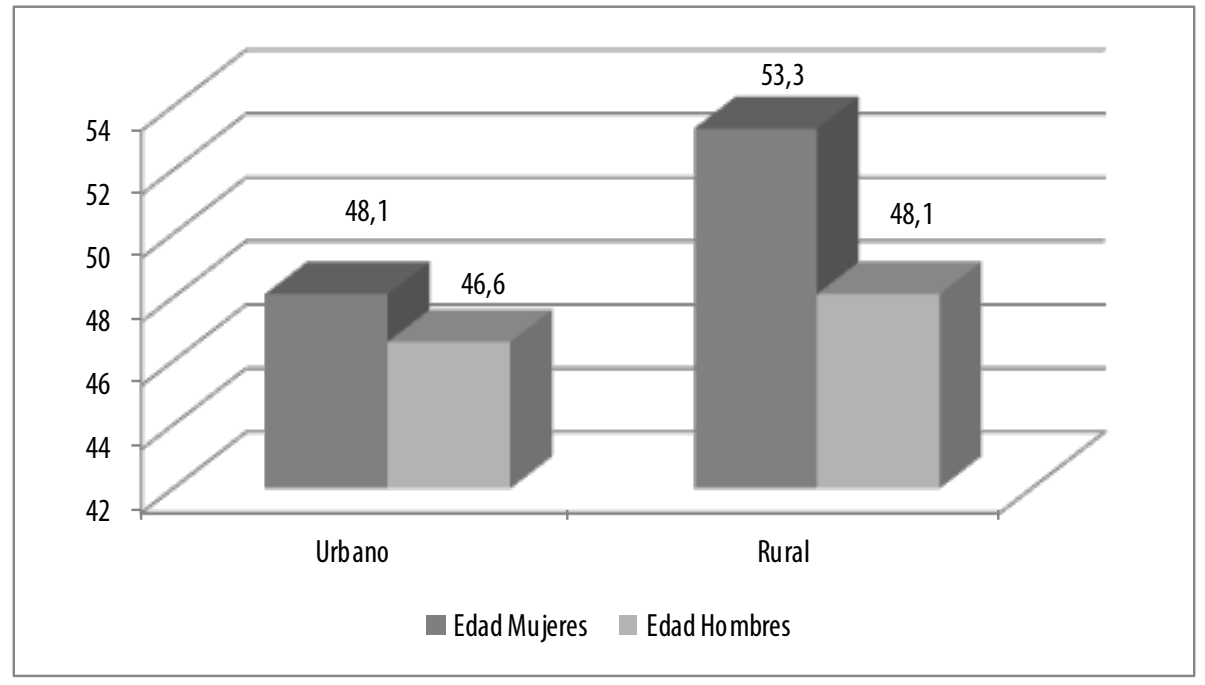

Fuente: elaboración propia con información de la ECV - DANE (2011)

La edad promedio del jefe hombre es 47 años y de la jefa mujer es de 50 años. En la zona rural, la edad promedio de las jefas caucanas es mayor que la de los jefes en 5 años; situación similar a la que ocurre en la ciudad, aunque la diferencia entre ellos es menor, cercana a 1.5 años. Cabe anotar que sin importar el género, los hombres y las mujeres que son jefes de hogar en el campo, son mayores en edad que los similares en la zona urbana.

\subsubsection{Niveles de escolaridad en los hogares}

Al igual que en el resto del país, los años de educación de los jefes de hogar caucanos son siempre superiores en las ciudades con respecto al campo. Para el departamento del Cauca se encuentra que en el área urbana son 7.3 años de educación promedio para jefes o jefas de hogar y 4.2 años para él o la cónyuge, mientras que en la zona rural son 3.9 y 2.6, de manera respectiva. Cabe señalar que para la zona urbana, el jefe(a) casi dobla en años de educación al cónyuge, mientras que en el campo se repite el patrón, pero los años de educación que los separan son de un poco más de un año. 
Gráfico 4. Años de educación promedio del jefe y cónyuge, rural y urbano

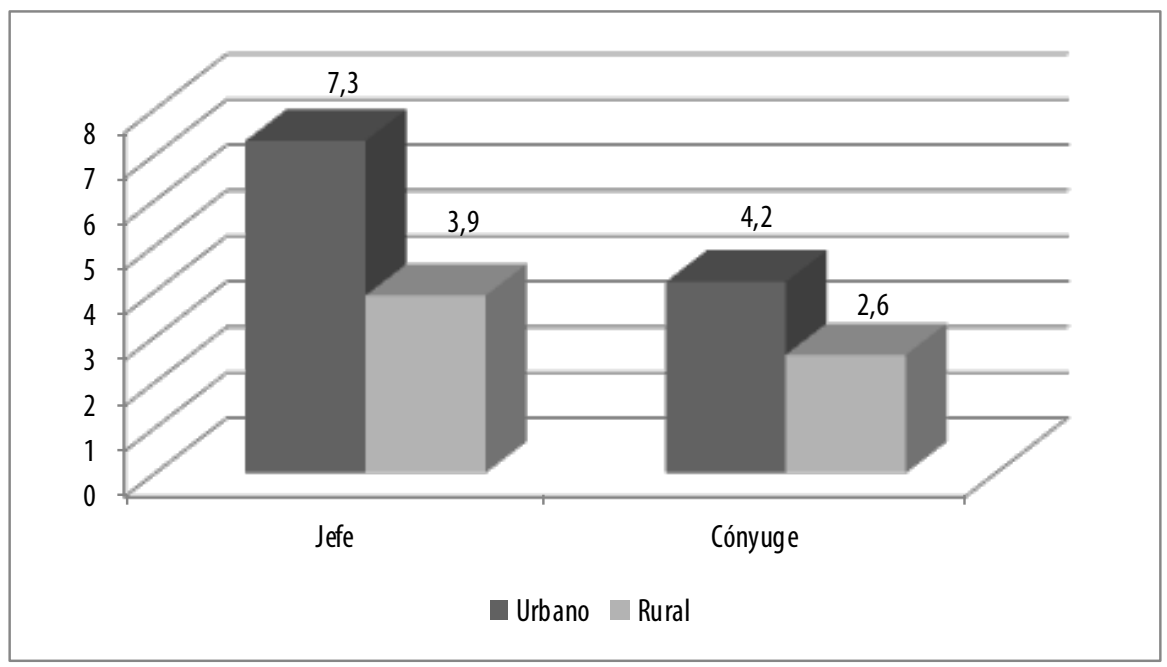

Fuente: elaboración propia con información de la ECV - DANE (2011)

Gráfico 5. Nivel de educación del jefe(a) del hogar y su cónyuge

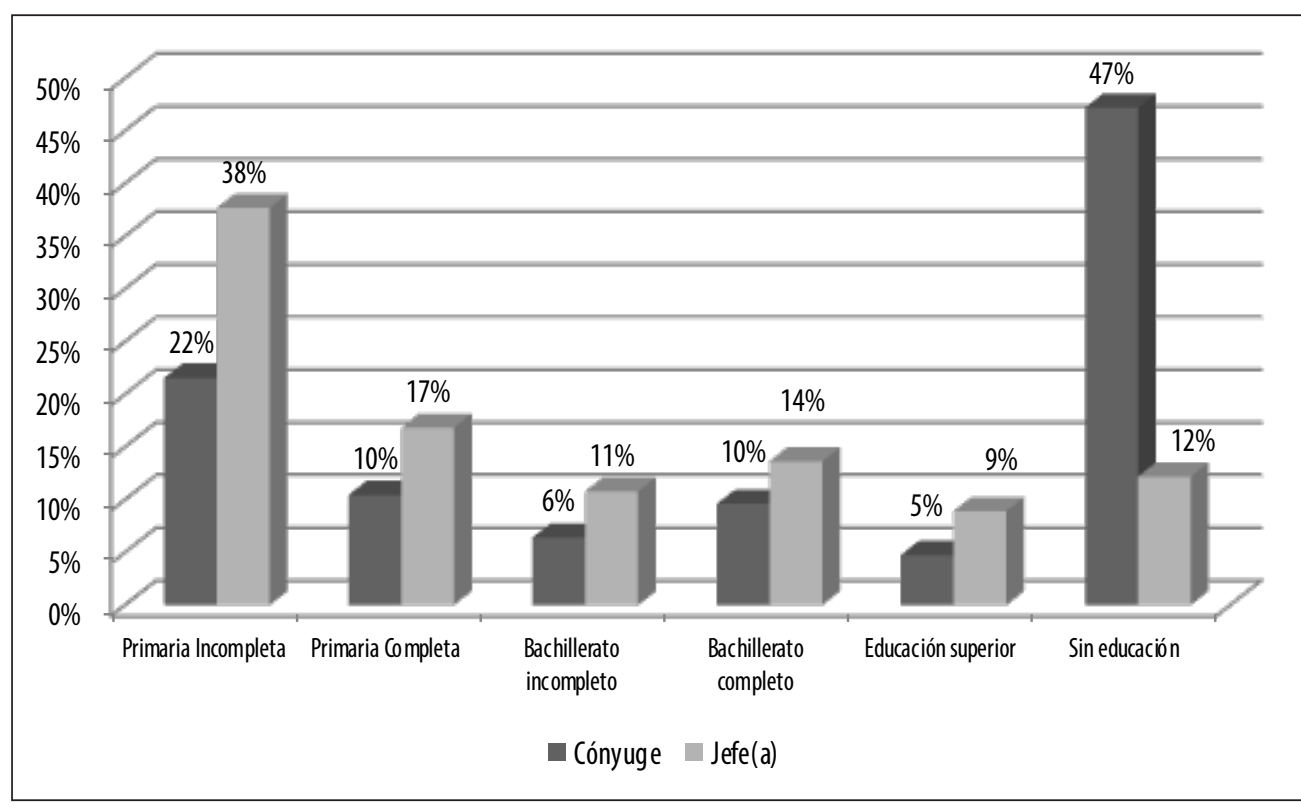

Fuente: elaboración propia con información de la ECV - DANE (2011)

De los 2,290 jefes de hogar de la encuesta el 12\% manifestó no tener años de educación, el 38\% primaria incompleta, seguidos del 17\% de los jefes que habían 
terminado su primaria, el bachillerato completo solo lo tienen el $14 \%$ de los jefes. Frente al nivel educativo universitario o con estudios de postgrado, tan solo el 9\% de los jefes de hogar manifestaron tener este nivel de escolaridad. El bajo nivel de escolaridad constituye otro indicador de pobreza para una región, por lo tanto este hallazgo refleja la realidad del departamento del Cauca, según el DANE uno de los más pobres del país, dado que existe una alta asociación entre un bajo nivel de escolaridad y los niveles de ingreso bajos.

Arriagada (2000, p. 70) explica que ésta relación de causalidad se da en ambos sentidos, es decir, la baja escolaridad causaría bajos niveles de ingreso, pero también los bajos niveles de ingreso afectarían de forma negativa los niveles de escolaridad, así una de las causas del ausentismo escolar podría ser la falta de capacidades económicas.

El panorama es igual de preocupante cuando se analiza el nivel de educación del jefe(a) del hogar en comparación con el cónyuge, para el caso de éste último, el 47\% de ellos manifestaron no tener ningún año de educación, mientras que para el/la jefe(a) del hogar ese porcentaje es mucho menor (12\%), de otro lado el $22 \%$ de los cónyuges hicieron la primaria completa, y tan solo un 5\% alcanza algún tipo de estudios de nivel superior. En términos generales, esto indica que en el departamento, así como en otras regiones del país, el nivel de formación de los jefes y los cónyuges es muy bajo, lo que explica en parte por qué los hogares caucanos son más vulnerables a entrar en situaciones de pobreza.

\subsection{Tipología de los hogares}

Adicional a los hallazgos de la ECV 2011 sobre el género del jefe del hogar y su nivel educativo, la información también permite hacer inferencia sobre la estructura de los hogares, ya que como se analizó con antelación, hogares más grandes y jefes con menor formación académica son más vulnerables a entrar en situación de pobreza o pobreza extrema. Estudios como el de Duque, Herrera y Ospina (2013, p. 43) validan, a través de modelaciones econométricas, que para el caso colombiano existe una fuerte relación directa entre pobreza y bajos niveles educativos.

La tipología de hogar más frecuente en el Cauca es la nuclear con hijos (34.8\%), la cual se compone por el jefe del hogar, su cónyuge e hijos; seguido por el hogar extenso con hijos (13.71\%), compuesto por el jefe, cónyuge, hijos y parientes; luego se encuentran los hogares unipersonales (12.71\%), que se componen solo por la presencia del jefe y el nuclear monoparental (12.62\%), el cual se compone por el jefe del hogar y los hijos. Por otro lado, dentro de la tipología de hogares menos comunes 
en el Cauca encontramos el hogar compuesto extenso $(0.13 \%)$, el cual se compone por la presencia del jefe, cónyuge, hijos, parientes y no parientes, y en el mismo porcentaje se encuentra el no familiar, que se compone por el jefe y no familiares. También dentro de los hogares menos comunes se encuentra el hogar compuesto sin núcleo (0.39\%), compuesto por el jefe, parientes y no parientes.

Gráfico 6. Tipología de hogares en el Cauca

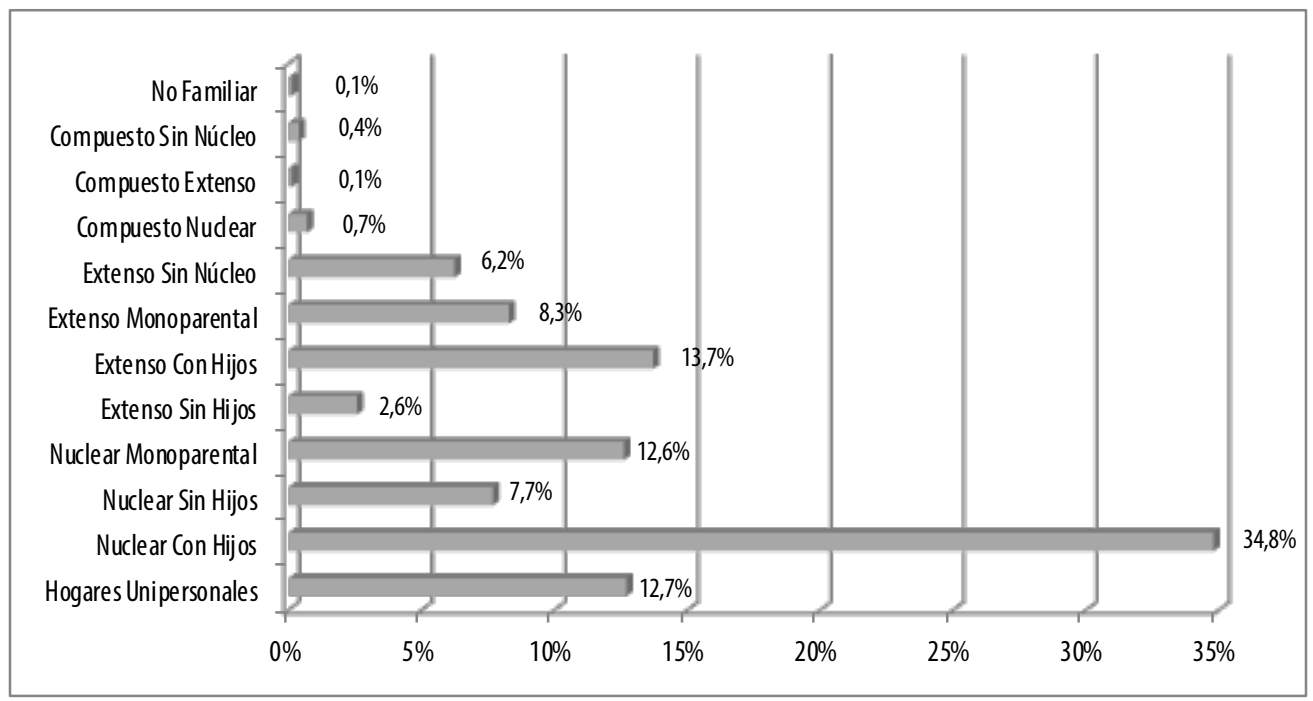

Fuente: elaboración propia con información de la ECV - DANE (2011)

De igual manera, el análisis de la tipología de los hogares en el departamento del Cauca puede diferenciarse entre zona rural y urbana. El anterior gráfico refleja un patrón similar en ambas zonas: el tipo de hogar más común es el nuclear con hijos, aunque de manera más acentuada en la zona rural (39.6\%) que en la urbana (30.0\%). A renglón seguido se encuentran en la cabecera: el hogar nuclear mono parental (15.1\%) y los hogares unipersonales (14.5\%), mientras que en la zona rural: los hogares extensos con hijos (15.1\%). También sobresale que en el campo no se presenta el tipo de hogar compuesto extenso ni el hogar compuesto sin núcleo, a diferencia de la zona urbana caucana donde se presentan todas las tipologías de hogares, aunque en un nivel muy bajo el tipo de hogar no familiar.

Estudios como el de Barahona (2006, p. 19) encuentran que la pobreza no se distribuye de manera aleatoria entre los distintos tipos de hogar, sino que tiende a afectar con mayor intensidad a algunos bien definidos, lo cuales adquieren la condición de "vulnerables a la pobreza". Estos hogares se definen en función del número de miembros, niños o dependientes y son propensos a caer en situación de pobreza. 
Gráfico 7. Tipología de hogares en el Cauca, rural y urbano

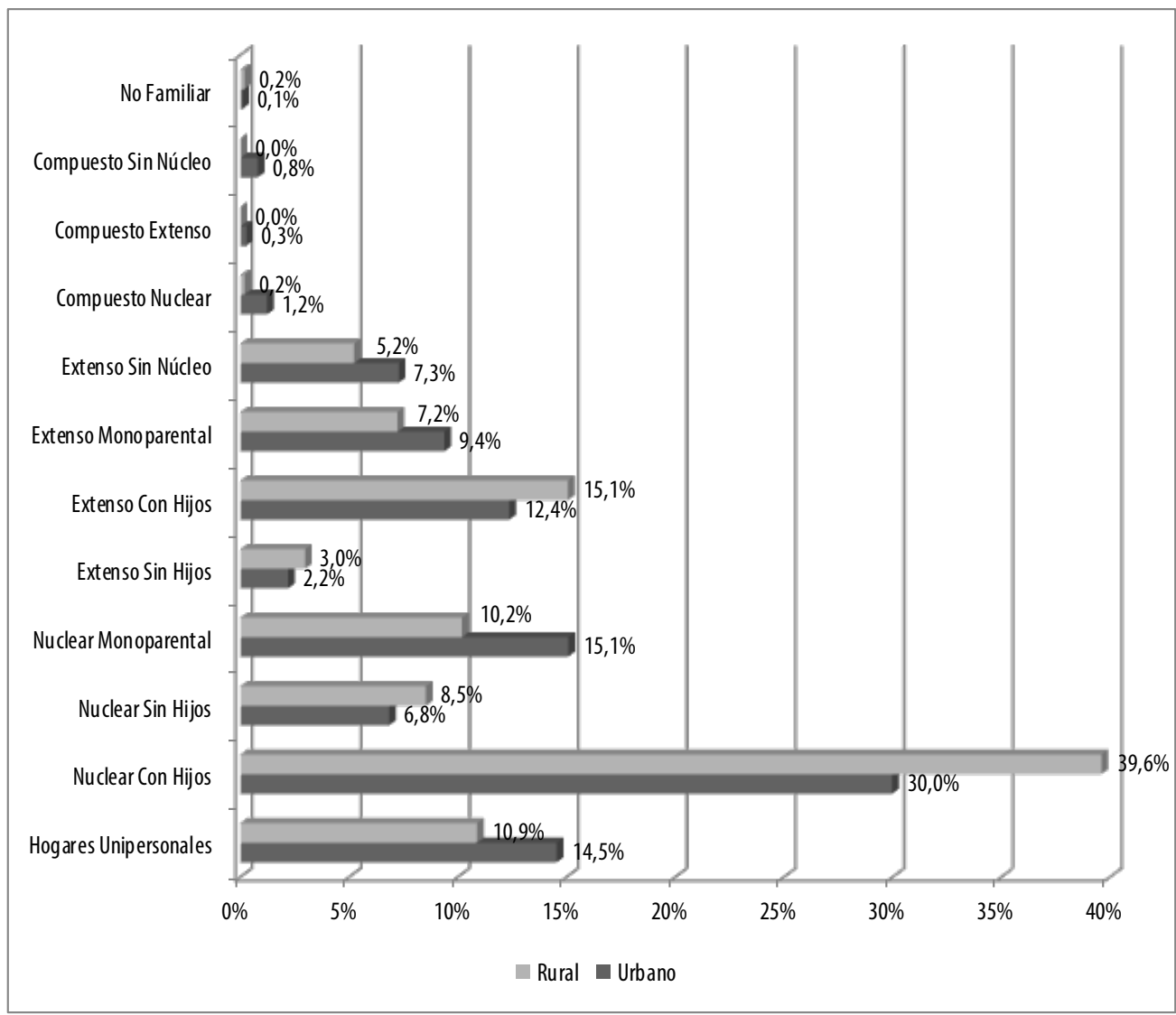

Fuente: elaboración propia con información de la ECV - DANE (2011)

Estudios como el de Barahona (2006, p. 19) encuentran que la pobreza no se distribuye de manera aleatoria entre los distintos tipos de hogar, sino que tiende a afectar con mayor intensidad a algunos bien definidos, lo cuales adquieren la condición de "vulnerables a la pobreza". Estos hogares se definen en función del número de miembros, niños o dependientes y son propensos a caer en situación de pobreza.

\subsection{Ciclo de Vida de los hogares}

Otros hogares suelen aparecer como vulnerables a la pobreza y se definen por su composición o estructura, por las etapas o ciclo de vida del hogar. Este análisis del ciclo de vida familiar de los hogares en el Cauca se hace en torno al concepto tradicional del mismo, es decir que solo considera la experiencia de los hogares 
que se componen del núcleo inicial (pareja de cónyuges con o sin hijos), puesto que esta clasificación se basa en la edad de la madre y en la edad de los hijos, sin abordar aquellos cuyo núcleo se ha disuelto o han pasado por el cambio a distintos tipos de agrupación (Barquero y Trejos, 2004), por ejemplo hogares no familiares u hogares con un jefe y otros parientes. Es por esto que el número de hogares según el ciclo de vida familiar es menor al número de hogares totales en el Cauca, siendo el primero 1,365 y el segundo 2,290. Así mismo, los hogares de parejas con hijos encontrados fueron 1,128 (83\%) y los de parejas sin hijos fueron 237 (17\%). Como se había afirmado, la clasificación a través del ciclo de vida se queda corta a la hora de representar la conformación de los hogares modernos, ya que solo bajo dicha clasificación cabe el $40.4 \%$ de los hogares caucanos y el restante $59.6 \%$ no pueden ser tenidos en cuenta.

Gráfico 8. Ciclo de vida de los hogares en el Cauca

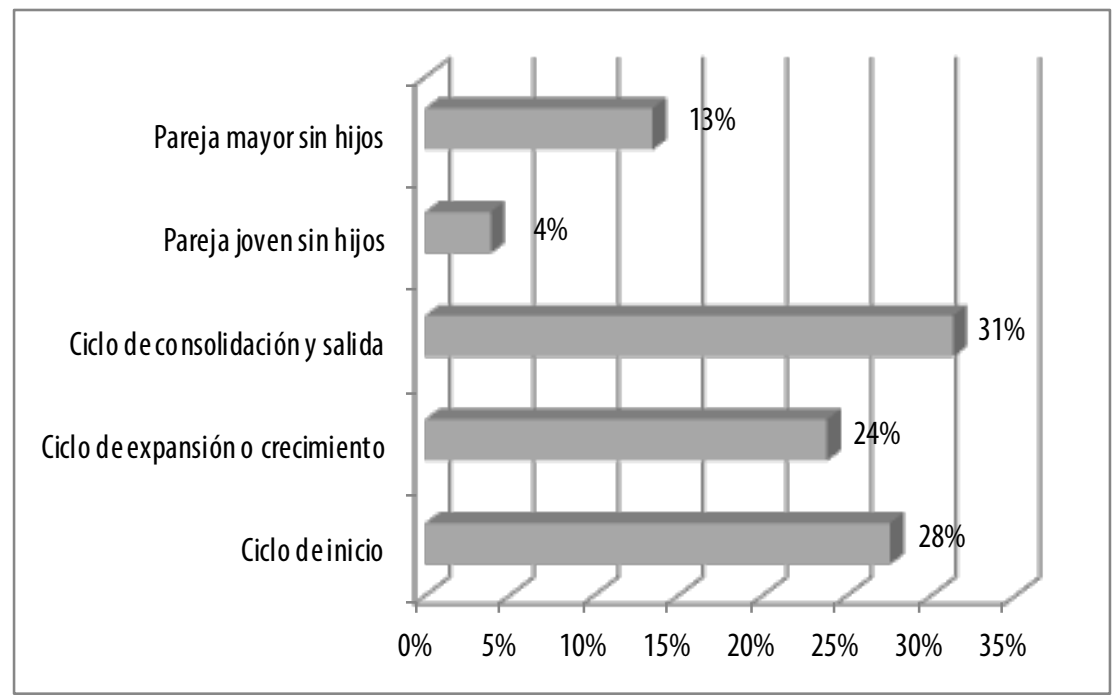

Fuente: elaboración propia con información de la ECV - DANE (2011)

Según el ciclo de vida familiar de los hogares, en el Cauca el más común es el hogar en consolidación y salida (31\%), seguido por el hogar en ciclo de inicio (28\%) y por el hogar en ciclo de expansión o crecimiento (24\%). En menores proporciones se encuentran los hogares de pareja mayor sin hijos y pareja joven sin hijos con un porcentaje de $13 \%$ y $4 \%$ respectivamente. Respecto a la baja representación de hogares compuestos por una pareja mayor sin hijos, los resultados muestran que no es considerable el número de personas que dejan las familias o núcleos iniciales conforme avanzan en edad, reduciendo así la concentración de personas mayores residiendo en hogares o familias sin hijos o solas, lo cual traería efectos sobre la 
Composición de los hogares y niveles de gastos en bienes y servicios básicos en el Departamento del Cauca, Colombia

vulnerabilidad frente a la pobreza, al considerar su limitada capacidad de generar ingresos y cubrirse frente a los riesgos propios de una avanzada edad.

Gráfico 9. Ciclo de vida de los hogares en el Cauca, rural y urbano

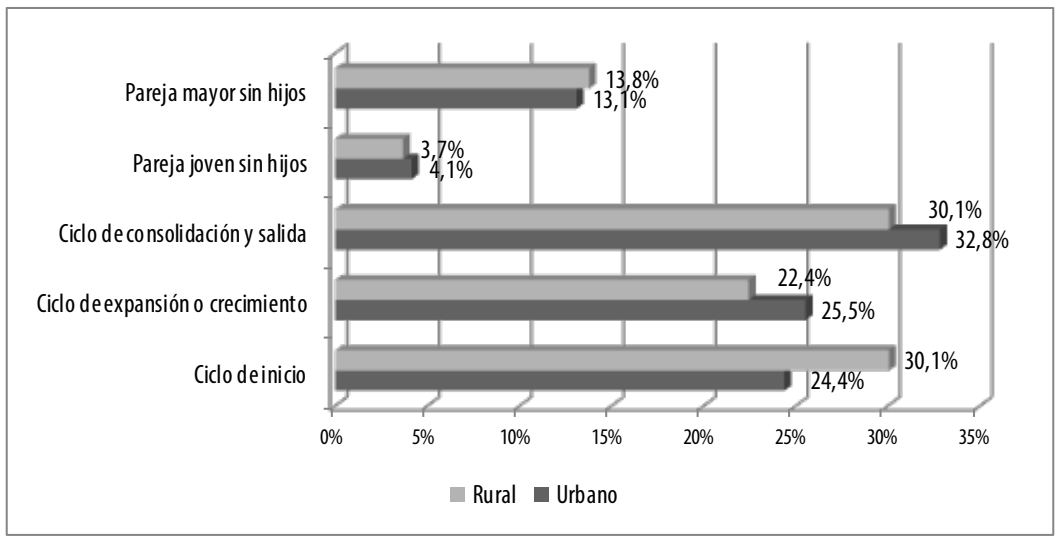

Fuente: elaboración propia con información de la ECV - DANE (2011)

De otro lado se puede analizar la tipología de los hogares, según el ciclo de vida, en el ámbito rural y urbano. Aunque en ambas zonas geográficas se observa la prevalencia de hogares en etapa de consolidación y salida, es decir que han dejado de tener hijos, es un poco mayor en las cabeceras (32.8\%) que en resto (30.1\%). En este último también es significativa la participación de los hogares en ciclo de inicio (30.1\%), es decir aquellos en los que empiezan a nacer los hijos. En forma similar, la tipología menos común es la conformada por una pareja joven sin hijos, tanto en hogares rurales (3.7\%) como urbanos (4.1\%). De lo anterior puede afirmarse que la tipología del ciclo de vida de los hogares caucanos es análoga a la presentada por los similares latinoamericanos. Esto lo indica Arriagada y Aranda (2004, p. 50), quien revela que la mayoría de hogares latinoamericanos se encuentran en la etapa de expansión y consolidación, lo cual conlleva una fuerte presión sobre los recursos familiares, ya que el tamaño del hogar es mayor y la edad de los hijos, tanto mayores como menores, los hace económicamente dependientes.

Los conceptos de tipología y ciclo de vida de los hogares están asociados a patrones demográficos y socioculturales como la nupcialidad, la fecundidad, la esperanza de vida al nacer, la mortalidad, las estrategias de sobrevivencia, prácticas culturales de convivencia o cohabitación, las condiciones materiales de vida y el nivel socioeconómico de los miembros del hogar o familia. De esta manera, si se agrupan las categorías de consolidación y salida, la de expansión y la de pareja mayor sin hijos, todas alcanzarían el 68\%, sugiriendo una aparente consolidación de ciclos 
de vida familiar avanzados. Esto podría tener implicaciones sobre los patrones de consumo de los hogares, algo que se analizará a continuación.

\section{MODELO ECONOMÉTRICO}

De acuerdo con Cayuela (2010, p. 41), para capturar los gastos en bienes y servicios básicos dependiendo de la tipología del hogar para el Cauca, se implementa un modelo de análisis de varianza (ANOVA) multifactorial donde la variable dependiente es continua y las explicativas son todas categóricas. Gujarati (2004, p. 286) resalta que este tipo de modelos se utilizan para comparar si las diferencias entre los valores promedios de dos o más grupos son significativos desde el punto de vista estadístico.

De otro lado, para dar cuenta de la alta variabilidad en los datos, el modelo es estimado tanto en la zona rural como en la urbana del departamento, ya que los gastos deben ser disimiles entre ellos. Para no caer en problemas de multicolinealidad, se han implementado dos tipos de modelos: uno que solo contiene como variables explicativas a las 12 tipologías del hogar y otro que contiene los 5 diferentes tipos de ciclos de vida, siguiendo a Ramírez y Muñoz (2004) en su estudio para la CEPAL. En efecto, ambas clasificaciones guardan altas relaciones sobre todo en lo concerniente al número de hijos y las edades.

Por último, los gastos de los hogares se descomponen en ocho bienes y servicios de los cuales siete se consideran básicos y se adiciona los niveles de ahorro. En este orden de ideas, el modelo es el siguiente:

$$
\begin{aligned}
\text { Gasto }_{i}= & \beta_{1} \text { hunip }_{i}+\beta_{2} \text { nuchj }_{i}+\beta_{3} \text { nucshj }_{i}+\beta_{4} \text { nucmonop }_{i}+\beta_{5} \text { extshj }_{i}+\beta_{6} \text { extchj }_{i} \\
& +\beta_{7} \text { extmono }_{i}+\beta_{8} \text { extsnuc }_{i}+\beta_{9} \text { compnuc }_{i}+\beta_{10} \text { compuext }_{i}+\beta_{11} \text { compsinuc }_{i} \\
& +\beta_{12} \text { nofam }_{i}+U_{i}
\end{aligned}
$$

$$
\text { Gasto }_{i}=\alpha_{1} \text { hogini }_{i}+\alpha_{2} \text { hogexp }_{i}+\alpha_{3} \text { hogcon }_{i}+\alpha_{4} \text { parejov }_{i}+\alpha_{5} \text { parmay }_{i}+\varepsilon_{i}
$$

Donde los gastos se distribuyen en alimentos, educación, vestido, transporte, vivienda, salud, gastos personales y ahorro. Las variables explicativas del modelo 1 son el hogar unipersonal (hunip), nuclear con hijos (nuchj), nuclear sin hijos (nucsh), nuclear monoparental (nucmonop), extenso sin hijos (extsh), extenso con hijos (extchj), extenso monoparental (extmono), extenso sin núcleo (extsnuc), compuesta con núcleo (compnuc), compuesto extenso (compuext), compuesto sin núcleo (compsinuc), hogar no familiar (nofam). Para el modelo 2, son el hogar en inicio (hogini), hogar en expansión (hogexp), hogar en consolidación (hogcon), hogar de pareja joven (parejov), y el hogar 
Composición de los hogares y niveles de gastos en bienes y servicios básicos en el Departamento del Cauca, Colombia

de pareja mayor (parmay). Al final $U_{i}$ y $\varepsilon_{1}$ denotan los términos aleatorios de error, es decir aquellas variables que influyen en los gastos de bienes y servicios pero que no han sido consideradas de forma explícita en cada modelo de manera respectiva. Se asume que dichas variables cumplen con los supuestos cásicos de media cero, homocedasticidad y no autocorrelación, y siguen una distribución normal. Las estimaciones de forma ampliada se muestran en los anexos 1 y 2, de forma resumida se presentan a continuación.

Tabla 4. Gastos en bienes y servicios básicos de los diferentes tipos de hogar en el Cauca rural

\begin{tabular}{|c|c|c|c|c|c|c|c|c|c|c|c|c|c|c|c|c|c|c|c|c|c|c|}
\hline & HOGAR & & ALIM & Sig. & & EUC & Sig. & & AASPER & Sig. & AHORRO & Sig. & & SAL & Sig. & TRANS & Sig. & VEST & Sig. & & VIV & Sig. \\
\hline & HUNIP & $\$$ & 147.149 & *** & $\$$ & 10 & & $\$$ & 16.598 & *** & $\$ 22.935$ & & $\$$ & 17.298 & *** & $\$ 22.323$ & *** & \$ 11.851 & *** & $\$$ & 51.235 & *** \\
\hline & NUCHJ & $\$$ & 255.031 & $* * *$ & $\$$ & 21.479 & *** & $\$$ & 27.189 & $* * *$ & $\$ \quad 5.114$ & $* * *$ & $\$$ & 38.322 & *** & $\$ \quad 29.201$ & $* * *$ & \$ 18.078 & $* * *$ & $\$$ & 58.302 & *** \\
\hline & NUCSHJ & $\$$ & 225.424 & *** & $\$$ & 1.220 & & $\$$ & 20.599 & *** & $\$ 15.631$ & * & $\$$ & 64.572 & ** & $\$ \quad 25.078$ & *** & 11.282 & *** & $\$$ & 68.796 & *** \\
\hline & NUCMONOP & $\$$ & 201.255 & $* * *$ & $\$$ & 25.157 & *** & $\$$ & 22.027 & *** & 1.033 & & $\$$ & 20.578 & *** & $\$ 20.906$ & $* *$ & \$ 10.726 & $* * *$ & $\$$ & 52.924 & $* * *$ \\
\hline & EXTSHJ & $\$$ & 228.662 & *** & $\$$ & 8.349 & *** & $\$$ & 26.630 & *** & 1.303 & & $\$$ & 119.156 & & \$ 16.594 & *** & 12.069 & ** & $\$$ & 102.295 & ** \\
\hline & EXTCHJ & $\$$ & 281.901 & $* * *$ & $\$$ & 26.761 & *** & $\$$ & 31.093 & $* * *$ & 2.845 & ** & $\$$ & 45.270 & *** & $\$ 24.723$ & $* * *$ & \$ 20.771 & $* * *$ & $\$$ & 69.079 & $* * *$ \\
\hline & EXTMONO & $\$$ & 300.847 & *** & $\$$ & 27.391 & *** & $\$$ & 30.462 & *** & \$ 63.836 & & $\$$ & 66.996 & *** & \$ 18.372 & *** & $\$ 23.490$ & *** & $\$$ & 80.110 & *** \\
\hline & EXTSNUC & $\$$ & 210.671 & *** & $\$$ & 11.818 & *** & $\$$ & 21.121 & *** & $\$ \quad 1.733$ & & $\$$ & 25.661 & *** & $\$ 16.239$ & ** & \$ 15.781 & $* * *$ & $\$$ & 51.588 & *** \\
\hline & COMPNUC & $\$$ & 392.143 & $* * *$ & $\$$ & 10.788 & & $\$$ & 30.857 & *** & $\$$ & & $\$$ & 134.164 & ** & $\$ 18.333$ & *** & $\$ 33.333$ & & $\$$ & 35.253 & *** \\
\hline & NOFAM & $\$$ & 206.571 & *** & $\$$ & 19.432 & $* * *$ & $\$$ & 30.738 & *** & 205 & & $\$$ & 70.500 & & $\$ \quad 44.000$ & & $\$ 10.333$ & & $\$$ & 63.391 & *** \\
\hline 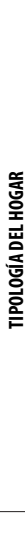 & R2 & & $5,2 \%$ & & & $0,7 \%$ & & & $2,9 \%$ & & $0,9 \%$ & & & $1,8 \%$ & & $0,4 \%$ & & $1,2 \%$ & & & $1,2 \%$ & \\
\hline \multirow{6}{*}{ 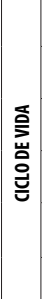 } & HOGINI & $\$$ & 247.475 & $* * *$ & $\$$ & 22.794 & *** & $\$$ & 29.310 & *** & $\$ \quad 1.600$ & ** & $\$$ & 34.901 & *** & $\$ 28.164$ & $* * *$ & $\$ 23.332$ & *** & $\$$ & 55.781 & $* * *$ \\
\hline & HOGEXP & $\$$ & 275.693 & *** & $\$$ & 31.880 & *** & $\$$ & 27.936 & *** & \$ 10.057 & ** & $\$$ & 46.858 & *** & $\$ 35.005$ & *** & $\$ 20.305$ & *** & $\$$ & 69.314 & *** \\
\hline & HOGCON & $\$$ & 268.431 & *** & $\$$ & 16.389 & *** & $\$$ & 27.539 & *** & 3.202 & $* * *$ & $\$$ & 40.652 & *** & $\$ 22.480$ & $* * *$ & $\$ 13.408$ & *** & $\$$ & 60.631 & *** \\
\hline & PAREJOV & $\$$ & 279.536 & *** & $\$$ & 8.285 & ** & $\$$ & 32.453 & *** & \$ 34.441 & & $\$$ & 59.784 & ** & \$ 51.812 & * & \$ 15.345 & *** & $\$$ & 119.538 & ** \\
\hline & PARMAY & $\$$ & 212.814 & $* * *$ & $\$$ & 1.633 & *** & $\$$ & 19.350 & *** & 5.826 & * & $\$$ & 85.026 & ** & \$ 15.122 & $* * *$ & \$ 10.346 & *** & $\$$ & 65.811 & *** \\
\hline & R2 & & $3,9 \%$ & & & $3,0 \%$ & & & $2,7 \%$ & & $1,0 \%$ & & & $3,5 \%$ & & $1,6 \%$ & & $4,1 \%$ & & & $1,3 \%$ & \\
\hline
\end{tabular}

NOTAS: Estimación bajo consistencia a la White.

Sig.: significancia estadística: ${ }^{*} 10 \%,{ }^{*} 5 \%,{ }^{* *} 1 \%$.

Fuente: elaboración propia con información de la ECV - DANE (2011)

Los resultados estadísticos reflejan en general muy buenos ajustes sobre todo en la parte individual, ya que la gran mayoría generan p-valores muy bajos. La única variable que no tiene este comportamiento es la relacionada con los gastos en ahorro, donde muy pocas tipologías y ciclos de vida de los hogares resultan ser significativos. Las medidas de bondad de ajuste son bajas, pero como se afirma en Gujarati (2004, p. 288) esto es típico de los modelos ANOVA pues solo se utilizan 
para determinar la significancia estadística de la diferencia entre valores promedios sin explicar de dónde provienen las mismas, es decir su valor es bajo porque no contienen variables explicativas adicionales.

Frente a la tipología de los hogares se puede observar que sin importar la clasificación, los mayores niveles de gasto promedio en orden descendente son alimentos, vivienda, transporte y educación, siendo el ahorro el bien que menos se destina recursos por parte de los caucanos.

En términos específicos el hogar unipersonal, es decir aquel que solo está conformado por el jefe, muestra gastos promedio en educación casi nulos, lo cual puede estar asociado de manera lógica a la falta de hijos. De otro lado, como se esperaba, los hogares extensos con hijos y los nucleares con hijos son los que mostraron mayor gasto en todos los rubros analizados, seguidos solo del extenso monoparental. Esto obedece a que un hogar con hijos que está en crecimiento exige una alta demanda de bienes y servicios básicos, al igual que los hogares con un número mayor de integrantes, debido a la inclusión de parientes por ejemplo, implican también mayores niveles de consumo.

Cabe destacar que la tenencia de hijos lesiona los niveles de ahorro, pues para los hogares nucleares con hijos asciende a \$5,114 por mes; mientras que para aquellos que son nucleares también pero sin hijos asciende a $\$ 15,631$, cerca del triple. Por último, los compuestos nucleares, es decir aquellos que tienen jefe, cónyuge, hijos y no parientes gastan mucho más en alimentos y salud, pero muy poco en educación y vivienda, lo cual es síntoma de posible hacinamiento y bajos niveles de capital humano, situación que ya se había mencionado. En efecto, de acuerdo con la Secretaría de Educación del Departamento del Cauca SEDCAUCA (2011, p. 4), los estudiantes en el área rural terminan la primaria pero muy pocos acceden a secundaría y solo un número reducido (un poco menos de la cuarta parte) de ellos logra graduarse de bachilleres.

Si se analizan los gastos para los diferentes tipos de hogares en el componente del ciclo de vida, se encuentra que en la etapa de vejez o parejas mayores, éstos muestran un menor consumo en alimentos, educación y ahorro, pero la demanda que realizan por salud es de las más elevadas, lo cual resulta casi evidente. De nuevo los hogares en expansión lideran el consumo de alimentos, educación y vestido; pero les queda poco para el ahorro. De manera contraria, las parejas jóvenes pagan más por vivienda (al parecer por gastos de alquiler) que por vestido y educación. Los niveles de ahorro resultan significativos para hogares con menos integrantes. Los nucleares y los extensos con hijos, muestran representatividades estadísticas en este gasto. Aunque los montos son bajos, frente al mostrado por 
Composición de los hogares y niveles de gastos en bienes y servicios básicos en el Departamento del Cauca, Colombia

los hogares nucleares sin hijos, los cuales ascienden a \$15,631. Las estimaciones de forma ampliada se muestran en los anexos 3 y 4, de forma resumida se presentan a continuación.

Tabla 5. Gastos en bienes y servicios básicos de los diferentes tipos de hogar en el Cauca urbano

\begin{tabular}{|c|c|c|c|c|c|c|c|c|c|c|c|c|c|c|c|c|c|c|c|}
\hline & HOGAR & ALIM & Sig. & & EDUC & Sig. & GASPER & Sig. & AHORRO & Sig. & & SAL & Sig. & TRANS & Sig. & VEST & Sig. & VIV & Sig. \\
\hline \multirow{11}{*}{ 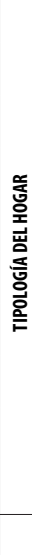 } & HUNIP & \$ 261.243 & *** & $\$$ & 4.261 & $* * *$ & $\$ 56.162$ & *** & 96.379 & & $\$$ & 67.038 & $* * *$ & $\$ 37.351$ & *** & $\$ 23.386$ & $* * *$ & $\$ 207.169$ & $* * *$ \\
\hline & NUCHJ & $\$ 456.681$ & *** & $\$$ & 71.249 & *** & $\$ 70.059$ & *** & $\$ \quad 42.755$ & & $\$$ & 109.896 & *** & $\$ 74.399$ & *** & \$ 42.747 & $* * *$ & $\$ 266.194$ & *** \\
\hline & NUCSHJ & $\$ 441.640$ & *** & $\$$ & 4.991 & & \$ 73.497 & *** & 76.840 & & $\$$ & 180.030 & $* * *$ & $\$ 75.676$ & *** & $\$ \quad 40.423$ & $* * *$ & $\$ 273.740$ & *** \\
\hline & NUCMONOP & $\$ 353.766$ & *** & $\$$ & 42.211 & $* * *$ & $\$ \quad 63.813$ & *** & 4.926 & & $\$$ & 92.724 & *** & $\$ 29.550$ & *** & $\$ \quad 40.652$ & $* * *$ & \$ 214.427 & *** \\
\hline & EXTSHJ & \$ 419.820 & *** & $\$$ & 33.006 & $* * *$ & $\$ \quad 32.799$ & *** & $\$$ & & $\$$ & 85.162 & $* * *$ & $\$ \quad 48.239$ & * & 8.467 & & \$ 149.661 & *** \\
\hline & EXTCHJ & $\$ 482.443$ & *** & $\$$ & 95.722 & $* * *$ & $\$ 83.840$ & *** & $\$ \quad 12.688$ & & $\$$ & 211.623 & *** & $\$ 87.001$ & *** & $\begin{array}{ll}\$ & 43.217\end{array}$ & $* * *$ & $\$ 269.474$ & *** \\
\hline & EXTMONO & $\$ 429.569$ & *** & $\$$ & 77.584 & $* * *$ & $\$ 70.574$ & *** & 795 & ** & $\$$ & 154.362 & *** & $\$ \quad 30.709$ & *** & $\$ 31.255$ & $* * *$ & \$ 211.440 & *** \\
\hline & EXTSNUC & \$ 362.277 & *** & $\$$ & 47.474 & $* * *$ & $\$ \quad 69.177$ & *** & $\$ \quad 1.582$ & * & $\$$ & 97.806 & $* * *$ & $\$ \quad 47.145$ & *** & $\$ \quad 43.807$ & $* * *$ & $\$ 256.454$ & *** \\
\hline & COMPNUC & \$ 808.776 & *** & $\$$ & 482.459 & *** & $\$ 253.486$ & ** & \$ 114.834 & & $\$$ & 393.915 & *** & $\$ 212.067$ & *** & \$ 120.714 & ** & $\$ 587.922$ & *** \\
\hline & NOFAM & $\$ 1.094 .857$ & *** & $\$$ & 177.447 & ** & $\$ 447.055$ & * & \$ 1.151 & & & 409.314 & $* * *$ & $\$ 336.067$ & & \$ 118.889 & ** & \$ 968.210 & *** \\
\hline & R2 & \$ 704.271 & *** & $\$$ & 102.302 & ** & \$ 158.056 & *** & 5.685 & & $\$$ & 260.414 & $* * *$ & $\$ 242.195$ & *** & $\$ 90.370$ & $* * *$ & $\$ 416.340$ & *** \\
\hline \multirow{6}{*}{ 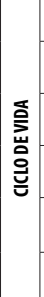 } & HOGINI & $6,8 \%$ & & & $16,9 \%$ & & $5,6 \%$ & & $0,4 \%$ & & & $4,3 \%$ & & $6,0 \%$ & & $2,4 \%$ & & $4,3 \%$ & \\
\hline & HOGEXP & \$ 388.557 & *** & $\$$ & 80.879 & *** & $\$ \quad 60.352$ & *** & $\$ \quad 19.241$ & * & $\$$ & 101.660 & $* * *$ & $\$ 72.382$ & $* * *$ & $\$ \quad 42.028$ & $* * *$ & $\$ 261.046$ & $* * *$ \\
\hline & HOGCON & \$ 502.733 & *** & $\$$ & 116.808 & *** & $\$ 88.468$ & $* * *$ & $\$ \quad 12.326$ & & $\$$ & 136.341 & $* * *$ & $\$ 96.101$ & $* * *$ & $\$ 56.236$ & $* * *$ & $\$ 280.472$ & *** \\
\hline & PAREJOV & $\$ 525.562$ & *** & $\$$ & 77.137 & $* * *$ & \$ 91.653 & *** & $\$ \quad 67.151$ & & $\$$ & 191.247 & $* * *$ & $\$ 82.006$ & $* * *$ & $\$ \quad 40.006$ & $* * *$ & $\$ 293.802$ & $* * *$ \\
\hline & PARMAY & $\$ 463.440$ & *** & $\$$ & 16.538 & & \$ 95.508 & *** & 8.482 & * & $\$$ & 83.220 & *** & $\$ 70.331$ & $* * *$ & $\$ 50.907$ & $* * *$ & $\$ 342.641$ & *** \\
\hline & R2 & \$ 424.991 & $* * *$ & $\$$ & 10.139 & *** & $\$ 53.083$ & *** & \$ 73.183 & & $\$$ & 182.904 & *** & $\$ \quad 67.879$ & $* * *$ & \$ 26.481 & *** & $\$ 214.656$ & *** \\
\hline
\end{tabular}

NOTAS: Estimación bajo consistencia a la White.

Sig.: significancia estadística: ${ }^{*} 10 \%,{ }^{*} 5 \%,{ }^{* *} 1 \%$.

Fuente: elaboración propia con información de la ECV - DANE (2011)

Los resultados igual que en el caso anterior, muestran en general buenos ajustes individuales, debido a bajos p-valores. En este mismo sentido, la variable ahorro no cumple con dicha tendencia tanto para las tipologías y los ciclos de vida. En todos los modelos, el $\mathrm{R}^{2}$ es bajo, pero por lo explicado con anterioridad, es un comportamiento normal para estos modelos.

En las ciudades, los hogares más numerosos gastan más en bienes y servicios que en el área rural. Esto obedece a varios factores entre los cuales se destacan las oportunidades laborales, académicas y en general la mayor disponibilidad de ofertas de bienes y servicios. También se observa que los gastos más elevados, independiente de la tipología del hogar o del ciclo de vida en el que se encuentren, 
son en alimentos, vivienda y salud, y los que menos desembolsos reportan son en vestido y educación. Frente al ahorro, la gran mayoría no resultan significativos.

En términos específicos llama la atención que a pesar de que los hogares compuestos extensos son los que mayor gasto generan al mes en bienes y servicios básicos, presentan desembolsos muy bajos en educación. Esto puede indicar que debido al creciente número de personas que conforman el hogar, hay que elegir entre una amplia gama de bienes bajo restricciones presupuestales bajas y el que menos ponderan es la educación, situación de la que se tenía indicio con antelación. Pero de igual forma, la presencia no solo de los padres e hijos sino también de familiares y no parientes en un solo núcleo eleva las demandas por los otros bienes considerados. Como se puede observar, los niveles de gasto en alimentos superan el millón de pesos al mes por encima del realizado en vivienda $(\$ 968,210)$ y en gastos personales $(\$ 447,055)$. Cabe destacar también que los niveles de ahorro no son significativos.

Del lado del ciclo de vida, los hogares en consolidación (aquellos cuyos hijos menores tienen 13 años o más), al lado de los hogares en expansión (aquellos cuyos hijos menores tienen hasta 12 años) son los que registran mayores niveles de consumo, pero existe una diferencia muy marcada en los gastos por educación, pues alcanzan casi el doble para hogares con hijos pequeños. Como se espera, los hogares conformados por una persona muestran los gastos más bajos en alimentos, educación y transporte, pero los más altos en niveles de ahorro, lo cual refuerza el resultado anterior.

En cuanto a los hogares de parejas jóvenes, es decir donde no han tenido hijos y en la cual la mujer tiene menos de 40 años, los gastos personales son altos $(\$ 77,137)$ al igual que los realizados en vivienda $(\$ 116,808)$. En estos hogares no hay hijos y los integrantes no son longevos, por lo que podrían gastar más recursos en ellos mismos y también podrían asegurar una residencia.

Por último, los niveles de ahorro solo son significativos para los hogares extensos pero no sobrepasan \$1,600; es decir son muy bajos. Para este mismo rubro, pero en el ciclo de vida, los hogares en inicio (aquellos con familias que sólo tienen hijos menores de seis años) y los de parejas jóvenes, los ahorros son mayores y llegan a ser inferiores a $\$ 20,000$.

\section{CONCLUSIONES}

El 70\% de los hogares caucanos, están conformados por jefes de hogar hombres que en promedio registran una edad de 47.4 años, acompañados de 5.7 años de educación, mientras que los cónyuges registran un promedio de 4.5 años de esco- 
Composición de los hogares y niveles de gastos en bienes y servicios básicos en el Departamento del Cauca, Colombia

laridad. En los hogares donde el jefe es una mujer (30\%), su edad oscila en los 50 años y los años de educación en 5.2. En términos desagregados, en el área rural los hogares que tienen por jefe a un hombre son el 76\%, cuya edad media es 48.1 años, registran 4 años de educación promedio y los parejas alcanzan 3.3. En aquellos hogares donde la mujer es la cabeza (34\%), su edad alcanza los 53 años y los años registrados de educación ascienden a 3.5. En el área urbana, el 64\% de los hogares tienen por cabeza a un hombre y $36 \%$ a una mujer. La edad de los jefes alcanzan los 46.6 años, y los niveles de educación son de 7.7 años y los cónyuges 6.1. Para los restantes hogares donde los jefes son mujeres (36\%), las edades oscilan en 48 años y los años invertidos en educación no alcanzan el año.

Lo anterior muestra que ya sea en el campo o en la ciudad, en la mayoría de los hogares caucanos el jefe es hombre, y los niveles de escolaridad son más altos que en las mujeres (aunque no deja de ser un nivel de escolaridad bajo), superando éstas a los hombres solo en edad. Llama la atención que si bien los jefes hombres en las ciudades presentan mayores niveles de estudio que los semejantes en el área urbana, en el género opuesto no ocurre lo mismo, toda vez que las jefas de la zona urbana tienen menor grado de escolaridad que los pares de las áreas rurales. Esto muestra en primera instancia que los hogares en el departamento del Cauca siguen un modelo patriarcal donde los hombres a diferencia de las mujeres son quienes aportan la mayoría de los ingresos del hogar, trabajan y pueden acceder a mayores niveles de educación (por lo menos en las ciudades). De otro lado, la brecha existente entre los hogares rurales y urbanos cada vez será más amplia en el Cauca, pues a pesar que las mujeres en el área rural muestran mayores niveles de escolaridad que los hombres, en el campo esto importa poco, porque ellas no están inmersas en la dinámica del mercado laboral de las ciudades, y por tanto un mayor capital humano no implica mayores remuneraciones económicas.

Los hogares más comunes en el área rural y urbana en el departamento del Cauca son los nucleares con hijos, es decir aquellos que están conformados por el jefe, el cónyuge, y los hijos, aunque su proporción es mayor en el campo que en las ciudades. En el área rural del departamento no existen familias compuestas extensas ni compuestas sin núcleo, mientras que en las ciudades existen todas las tipologías, siendo la menos frecuente la no familiar, es decir aquellas que tienen solo al jefe y a no parientes. Contario a lo que se podría esperar, los hogares más numerosos es decir los compuestos nucleares, tanto extensos y sin núcleos, se encuentran en mayor proporción en el área urbana y no en la rural.

Del lado del ciclo de vida, se encuentra que en la zona urbana del Cauca la mayoría de los hogares se encuentra en la etapa de consolidación, es decir existen 
muchas familias que tienen hijos menores de 13 años o más; mientras que en la parte rural hay prevalencia de hogares en etapas de inicio, es decir familias que sólo tienen hijos menores de seis años. Esto traduce que la tasa de dependencia en los hogares debe ser muy alta en el departamento, es decir que existe una mayor proporción de población dependiente (niños y ancianos) frente a la población productiva (adultos), por lo que muy pocas personas aportan ingresos en el hogar ya que hay muchos menores de edad.

Sin importar la tipología de los hogares, los gastos mínimos en bienes y servicios en términos absolutos siempre son más elevados en la zonas urbanas que en las rurales, pero en términos relativos la situación cambia, ya que los gastos en alimentos son más elevados en el campo, al igual que la salud, y el ahorro. En el campo, los gastos más elevados son en alimentos y vivienda, y a continuación se encuentra la salud y los gastos personales. Cabe destacar que los desembolsos en educación son muy bajos, ubicados en la penúltima posición, solo superados por el ahorro. En las ciudades, el patrón es el mismo, pero como era de esperarse el transporte ingresa como uno de los más demandados.

Los niveles de gasto, sin considerar si se toma el Cauca como un todo o si se clasifica en zona urbana o rural, por lo general guardan una relación directa con los hogares que presentan un mayor número de integrantes, con los hogares compuestos extensos, es decir aquellos que presentan jefe, cónyuge, hijos, parientes y no parientes. En los ciclos de vida, la situación es similar en los hogares cuyos hijos menores tienen hasta 12 años, es decir en los hogares en crecimiento o expansión.

El comportamiento de los niveles de gasto es igual a la tipología de los hogares, es decir, mayores en niveles absolutos para las ciudades que para el campo, aunque en términos relativos también se mantiene el patrón, los alimentos en el área rural ocupan un poco más de la mitad de los gastos, mientras que en la urbana es alrededor de la tercera parte. Por componentes, el área rural gasta más en alimentos y de nuevo muy poco en educación y ahorro; aunque en las ciudades sucede algo similar, los desembolsos en educación duplican a los del campo. Esto evidencia que las brechas entre las zonas rurales y urbanas cada vez son más amplias debido a que la inversión en capital humano es mucho más elevada en las urbes.

En los hogares caucanos ya sean rurales o urbanos, los niveles de ahorro son bajos. En términos absolutos se ahorra más en la ciudad y menos en el campo, pero en términos porcentuales, las situación es contraria toda vez que alcanzan el 2.2\% y $2.5 \%$ de los gastos totales. Los hogares más ahorradores en las ciudades son los compuestos nucleares y los que menos lo hacen son los extensos monoparentales, 
mientras que en el campo, son estos últimos los más ahorradores y los que más gastan y por tanto ahorran menos son los nucleares monoparentales. De acuerdo a su ciclo de vida, el ahorro en términos absolutos es superior en ambos escenarios, pero de manera porcentual son muy similares, 2.3\% para el área rural y 3.1\% para las zonas urbanas. En términos econométricos, el ahorro no resulta ser significativo desde el punto de vista estadístico, debido a que el ahorro es nulo para la gran mayoría de los hogares, evidenciando de alguna manera que los hogares caucanos gastan todo su ingreso en el consumo de bienes y servicios básicos y les queda poco o nada para ahorrar e invertir. Esto puede ser consistente con los elevados niveles de pobreza del departamento, la alta desigualdad del ingreso y los encumbrados niveles de desempleo.

En términos econométricos hay hogares que por su definición guardan relación con otros cuando la clasificación se realiza en el ámbito departamental. Es el caso de los hogares compuesto nuclear y compuesto sin núcleo, al parecer no solo por la presencia del jefe y los no parientes, sino por la gran prevalencia de ellos en el departamento. Todo lo anterior es fuente de multicolinealidad, pero la descomposición entre zonas rurales y urbanas diluyó el problema. De lado del ciclo de vida, su taxonomía es excluyente en su clasificación y por tanto no existió relación entre ellas, lo que facilitó las estimaciones y el logro de la consistencia estadística en los parámetros.

\section{BIBLIOGRAFÍA}

Ando, Albert. y Modigliani, Franco (1963). The 'life-cycle' hypothesis of saving: aggregate implications and tests. En: American Economic Review, Vol. 53, No. 1, p. 55-84.

Ando, Albert. y Modigliani, Franco (1957). Test of the life cycle hypothesis of savings: Comments and suggestions. En: Bulletin of the Oxford University Institute of Statistics, Vol. 19, No. 2, p. 99-124.

Argandoña, Antonio (1994). Factores determinantes del ahorro. En: Documentos de Investigación, No. 276, p. 1-99.

Arriagada, Camilo (2000). Pobreza en América Latina: Nuevos escenarios y desafíos de políticas para el hábitat urbano. En: CEPAL, Vol. 27, p. 1-68.

Arriagada, Irma. y Aranda, Verónica.(2004). Cambio de las familias en el marco de las transformaciones globales: necesidad de políticas públicas eficaces. En: CEPAL, Vol. 42, p. 1- 426.

Barahona, Milagros (2006). Familia, Hogares, Dinámica Demográfica, Vulnerabilidad y Pobreza en Nicaragua. En: CEPAL, No. 69, p. 1-83. 
Barquero, Jorge. y Trejos, Juan (2004). Tipos de hogar, ciclo de vida familiar y pobreza en Costa Rica 1987 - 2002. En: Población y Salud en Mesoamérica. San José, Costa Rica, Centro Centroamericano de Población, Vol. 2, No. 1, p. 1-36.

Cadarso, Marcos (2001) Ciclos de Vida del Hogar. En: Investigación y Marketing, No. 71, p. 12-18. Camacho, José. y Hernández, Manuel (2006). Consumo de servicios y ciclo vital: un análisis de los hogares españoles con datos de corte transversal. Documento de Trabajo, p. 1-26.

Cayuela, Luis (2010). Modelos lineales: Regresión, ANOVA y ANCOVA. Eco Lab, Centro Andaluz de Medio Ambiente, Universidad de Granada. Notas de clase, p.1-57.

CEPAL (2013). Trabajo decente e igualdad de género: políticas para mejorar el acceso y la calidad del empleo de las mujeres en América latina y el Caribe. Santiago de Chile, Editorial CEPAL, p. 1-234.

DANE (2014). Metodología Encuesta Nacional de Calidad de Vida 2012. [En línea] [Consultado Agosto 15 de 2014].

DANE (2012). Cauca: Pobreza Monetaria. Boletín de Prensa. [En línea] [Consultado Agosto 27 de 2014].

DANE (2011). Encuesta de Calidad de Vida (ECV), Cauca. [En línea]. [Consultado 14 de Septiembre de 2012].

DANE (2006). Ficha metodológica Gran Encuesta Integrada de Hogares. [En línea] [Consultado Agosto 26 de 2014].

De Gregorio, José (2007). Macroeconomía. Teoría y Políticas. Santiago de Chile, Pearson-Educación, p 1-781.

Duque, Rosa; Herrera, Andrés y Ospina, Martha (2013). Relación entre la educación y los componentes del índice de pobreza de Amartya Sen: Un análisis en Colombia. En: CIFE, Año 15, No. 23, p. 23-47.

Echeverri, Ligia (2004). La Familia en Colombia Transformaciones y Prospectiva. [En línea]. Cuadernos del CES (Centro de Estudios Sociales) [Consultado 02 de Agosto de 2014].

Fresneda, Oscar (2007). La medida de necesidades básicas insatisfechas (NBI) como instrumento de medición de la pobreza y focalización de programas. En: CEPAL, No. 18, p. 1-193.

Fuentes, Álvaro (1999). La vivienda como un activo de los hogares. En: CEPAL, Vol. 179, p. 1-20.

Gujarati, Damodar (2004). Econometría. México, Mc Graw-Hill Latinoamericana, Cuarta Edición,1002 p.

ICBF- Instituto Colombiano de Bienestar Familiar (2012). Caracterización de las familias en Colombia. Bogotá D.C. Subdirección de Familia. [En línea]. [Consultado 25 de Agosto de 2014]. 
Composición de los hogares y niveles de gastos en bienes y servicios básicos en el Departamento del Cauca, Colombia

Melo, Ligia; Zárate, Héctor. y Téllez, Juana (2006). El ahorro de los hogares en Colombia. En: Subgerencia estudios económicos. Banco de la República, No. 428, p. 1-55.

Modigliani, Franco (1986). Life Cycle, Individual Thrift, and the Wealth of Nations. En: American Economic Review, Vol. 76, No. 3, p. 297-313.

Modigliani, Franco y Brumberg, Richard (1954). Utility Analysis and the consumption function: An integration of cross section data. En: Post-keynesian Economics, de Kenneth Kurihara. New Brunswick NJ, Rutgers University Press, p. 388-436.

Moscoso. Andrés (2008). Características del Ahorro en el Ciclo de Vida. Tesis. Universidad De Chile, Santiago de Chile, p. 1-23.

Muñoz, Jorge (2009). Estimación de coeficientes de Orshansky a partir de un sistema completo de ecuaciones de demanda: una nueva metodología para la elaboración de umbrales de pobreza. En: Cuadernos de Economía, Vol. 28, No. 50, p. 191-221.

ORMET-Observatorio Regional del Mercado de Trabajo (2013). Informe de Diagnostico Mercado de Trabajo del Cauca. Popayán, PNUD, p. 1-99.

Profamilia (2010). Características Generales de los Hogares y la Población.[En línea] Profamilia.

Ramírez, Juan y Muñoz, Jorge (2004). Así son los Hogares en Soacha. Bogotá D.C., CEPAL. [En línea] [Consultado 01 de Agosto de 2014].

SEDCAUCA (2011). Descripción del Objeto de la Conformación del Banco de Oferentes. Popayán. Secretaría de Educación del Cauca. [En línea] [Consultado 08 de Septiembre de 2014].

Velásquez, Sandra (2010). Ser Mujer Jefa de Hogar en Colombia. En: Revista de la información básica, Vol. 4, No. 2, Revista Virtual. 


\section{ANEXOS}

\section{Anexo 1. Estimaciones Gastos en bienes y servicios. Cauca Rural. Tipología del Hogar}

\begin{tabular}{|l|r|r|l|r|r|}
\hline $\begin{array}{l}\text { Dependent Variable: ALIM } \\
\text { Method: Least Squares }\end{array}$ & & \\
\hline Date: 09/08/14 Time: $10: 55$ & & & \\
\hline Sample: 11149 & & & \\
\hline Included observations: 1149 & & & \\
\hline White heteroskedasticity-consistent standard errors \& covariance
\end{tabular}

Dependent Variable: SAL

Method: Least Squares

Date: 09/08/14 Time: 10:57

Sample: 11149

Included observations: 1149

White heteroskedasticity-consistent standard errors \& covariance

\begin{tabular}{|c|c|c|c|c|}
\hline Variable & Coefficient & Std. Error & t-Statistic & Prob. \\
\hline H_UNIP & 17298.3844 & 3894.69526 & 4.44152451 & 0.0000 \\
\hline NUC_HJ & 38322.2141 & 5008.35058 & 7.65166365 & 0.0000 \\
\hline NUC_SHJ & 64572.1234 & 27374.1502 & 2.35887226 & 0.0185 \\
\hline NUCMONOP & 20578.3603 & 5386.25538 & 3.82053185 & 0.0001 \\
\hline EXT_SHJ & 119155.516 & 86241.5021 & 1.38164935 & 0.1674 \\
\hline EXT_CHJ & 45270.2611 & 8258.99133 & 5.48133051 & 0.0000 \\
\hline EXT_MONO & 66995.8467 & 15822.4062 & 4.23423883 & 0.0000 \\
\hline EXT_SNUC & 25660.6404 & 6781.93779 & 3.78367381 & 0.0002 \\
\hline COMPNUC & 134164.384 & 62614.7037 & 2.14269773 & 0.0323 \\
\hline NOFAM & 70500 & 50069.3867 & 1.40804601 & 0.1594 \\
\hline R-squared & 0.01844703 & \multicolumn{2}{|c|}{ Mean dependent var } & 41538.1261 \\
\hline Adjusted R-squar & 0.01069112 & \multicolumn{2}{|c|}{ S.D. dependent var } & 150008.6831 \\
\hline S.E. of regression & 149204.648 & \multicolumn{2}{|c|}{ Akaike info criterion } & 26.67269043 \\
\hline Sum squared resi & i $2.5356 \mathrm{E}+13$ & \multicolumn{2}{|c|}{ Schwarz criterion } & 26.71661251 \\
\hline Log likelihood & -15313.4607 & \multicolumn{2}{|c|}{ Hannan-Quinn criter. } & 26.68927097 \\
\hline Durbin-Watson s & 1.87348611 & & & \\
\hline
\end{tabular}

\begin{tabular}{|c|c|c|c|c|}
\hline \multicolumn{5}{|c|}{ Dependent Variable: EDUC } \\
\hline \multicolumn{5}{|c|}{ Method: Least Squares } \\
\hline \multicolumn{5}{|c|}{ Date: 09/08/14 Time: 10:56 } \\
\hline \multicolumn{5}{|c|}{ Sample: 11149} \\
\hline \multicolumn{5}{|c|}{ Included observations: 1149} \\
\hline \multicolumn{5}{|c|}{ White heteroskedasticity-consistent standard errors \& covariance } \\
\hline Variable & Coefficient & Std. Error & t-Statistic & Prob. \\
\hline H_UNIP & 9.863013696 & 9.866511458 & 0.99964549 & 0.3177 \\
\hline NUC_HJ & 21479.29074 & 1247.047726 & 17.2241128 & 0.0000 \\
\hline NUC_SHJ & 1219.876992 & 817.9895332 & 1.49131125 & 0.1362 \\
\hline NUCMONOP & 25157.0425 & 4117.888952 & 6.10920858 & 0.0000 \\
\hline EXT_SHJ & 8348.90975 & 2786.079649 & 2.9966515 & 0.0028 \\
\hline EXT_CHJ & 26760.66735 & 2329.558908 & 11.4874396 & 0.0000 \\
\hline EXT_MONO & 27390.63278 & 3987.600868 & 6.86895045 & 0.0000 \\
\hline EXT_SNUC & 11817.96804 & 3524.750908 & 3.35285197 & 0.0008 \\
\hline COMPNUC & 10787.67124 & 7661.447976 & 1.40804601 & 0.1594 \\
\hline NOFAM & 19431.50685 & 2485.714232 & 7.81727304 & 0.0000 \\
\hline R-squared & 0.107378666 & \multicolumn{2}{|c|}{ Mean dependent var } & 18097.15355 \\
\hline Adjusted R-squar & 0.100325468 & \multicolumn{2}{|c|}{ S.D. dependent var } & 29283.14662 \\
\hline S.E. of regression & 27775.40852 & \multicolumn{2}{|c|}{ Akaike info criterion } & 23.31035484 \\
\hline Sum squared resi & $8.78708 \mathrm{E}+11$ & \multicolumn{2}{|c|}{ Schwarz criterion } & 23.35427692 \\
\hline Log likelihood & -13381.79885 & \multicolumn{2}{|c|}{ Hannan-Quinn criter. } & 23.32693538 \\
\hline Durbin-Watson s & 1.766245237 & & & \\
\hline
\end{tabular}

Dependent Variable: TRANS

Method: Least Squares

Date: 09/08/14 Time: 10:57

Sample: 11149

Included observations: 1149

White heteroskedasticity-consistent standard errors \& covariance

\begin{tabular}{|l|r|r|r|r|}
\hline Variable & Coefficient & Std. Error & t-Statistic & Prob. \\
\hline H_UNIP & 22323.09015 & 7444.521727 & 2.99859292 & 0.0028 \\
\hline NUC_HJ & 29200.70631 & 3861.823806 & 7.56137716 & 0.0000 \\
\hline NUC_SHJ & 25078.34332 & 8583.194271 & 2.92179607 & 0.0035 \\
\hline NUCMONOP & 20905.60155 & 8215.433151 & 2.54467429 & 0.0111 \\
\hline EXT_SHJ & 16594.08695 & 4224.677468 & 3.9278944 & 0.0001 \\
\hline EXT_CHJ & 24723.44604 & 3592.560499 & 6.88184543 & 0.0000 \\
\hline EXT_MONO & 18372.17048 & 5380.775174 & 3.41440961 & 0.0007 \\
\hline EXT_SNUC & 16238.7693 & 6361.611597 & 2.55261879 & 0.0108 \\
\hline COMPNUC & 18333.33334 & 1183.673442 & 15.4885061 & 0.0000 \\
\hline NOFAM & 44000 & 31248.97891 & 1.40804601 & 0.1594 \\
\hline R-squared & 0.003534691 & Mean dependent var & 24756.81354 \\
\hline Adjusted R-squar & -0.004339047 & S.D. dependent var & 74126.69441 \\
\hline S.E. of regression & 74287.33995 & Akaike info criterion & 25.27793384 \\
\hline Sum squared resi & $6.2857 E+12$ & Schwarz criterion & 25.32185593 \\
\hline Log likelihood & -14512.17299 & Hannan-Quinn criter. & 25.29451438 \\
\hline Durbin-Watson s & 1.796972877 & & & \\
\hline
\end{tabular}

Fuente: elaboración propia 


\section{Anexo 1. Estimaciones Gastos en bienes y servicios. Cauca Rural. Tipología del Hogar (Continuación)}

\begin{tabular}{|c|c|c|c|c|}
\hline \multicolumn{5}{|c|}{ Dependent Variable: GASPER } \\
\hline \multicolumn{5}{|c|}{ Method: Least Squares } \\
\hline \multicolumn{5}{|c|}{ Date: 09/08/14 Time: $10: 57$} \\
\hline \multicolumn{5}{|c|}{ Sample: 11149} \\
\hline \multicolumn{5}{|c|}{ Included observations: 1149} \\
\hline \multicolumn{5}{|c|}{ White heteroskedasticity-consistent standard errors \& covariance } \\
\hline Variable & Coefficient & Std. Error & t-Statistic & Prob. \\
\hline H_UNIP & 16598.3076 & 2084.93289 & 7.96107525 & 0.00000 \\
\hline NUC_HJ & 27188.8134 & 1282.95869 & 21.192275 & 0.00000 \\
\hline NUC_SHJ & 20599.3251 & 2034.62609 & 10.1243787 & 0.00000 \\
\hline NUCMONOP & 22026.6011 & 2196.29906 & 10.0289626 & 0.00000 \\
\hline EXT_SHJ & 26630.2828 & 5661.84571 & 4.70346317 & 0.00000 \\
\hline EXT_CHJ & 31093.0093 & 2176.16486 & 14.2879843 & 0.00000 \\
\hline EXT_MONO & 30462.477 & 3352.87798 & 3 9.08547141 & 0.00000 \\
\hline EXT_SNUC & 21120.7864 & 2503.70964 & 8.43579706 & 0.00000 \\
\hline COMPNUC & 30857.1429 & 10348.6878 & 2.98174449 & 0.00293 \\
\hline NOFAM & 30738.0952 & 4886.88036 & 6.28992179 & 0.00000 \\
\hline R-squared & 0.02927077 & \multicolumn{2}{|c|}{ Mean dependent var } & 25452.47017 \\
\hline Adjusted R-square & 0.02160039 & \multicolumn{2}{|c|}{ S.D. dependent var } & 26572.76645 \\
\hline S.E. of regression & 26284.2086 & \multicolumn{2}{|c|}{ Akaike info criterion } & 23.1999894 \\
\hline Sum squared resic & $7.8689 E+11$ & \multicolumn{2}{|c|}{ Schwarz criterion } & 23.24391148 \\
\hline Log likelihood & -13318.3939 & \multicolumn{2}{|c|}{ Hannan-Quinn criter. } & 23.21656994 \\
\hline Durbin-Watson st: & 1.64988534 & & & \\
\hline
\end{tabular}

Dependent Variable: VEST

Method: Least Squares

Date: 09/08/14 Time: 10:57

Sample: 11149

Included observations: 1149

White heteroskedasticity-consistent standard errors \& covariance

\begin{tabular}{|l|r|r|r|r|}
\hline Variable & Coefficient & Std. Error & t-Statistic & Prob. \\
\hline H_UNIP & 11850.6667 & 2449.93522 & 4.8371347 & 0.0000 \\
\hline NUC_HJ & 18078.0938 & 1705.28296 & 10.6012282 & 0.0000 \\
\hline NUC_SHJ & 11282.3129 & 3068.49446 & 3.67682363 & 0.0002 \\
\hline NUCMONOP & 10726.4957 & 1987.68861 & 5.39646687 & 0.0000 \\
\hline EXT_SHJ & 12068.6274 & 5299.89664 & 2.27714393 & 0.0230 \\
\hline EXT_CHJ & 20771.0983 & 3724.41802 & 5.57700509 & 0.0000 \\
\hline EXT_MONO & 23489.9598 & 4272.10142 & 5.49845556 & 0.0000 \\
\hline EXT_SNUC & 15780.5556 & 5190.38442 & 3.04034428 & 0.0024 \\
\hline COMPNUC & 33333.3333 & 23673.4689 & 1.40804601 & 0.1594 \\
\hline NOFAM & 10333.3333 & 7338.77535 & 1.40804601 & 0.1594 \\
\hline & & & & \\
\hline R-squared & 0.01247468 & Mean dependent var & 16584.07253 \\
\hline Adjusted R-squart & 0.00467159 & S.D. dependent var & 36374.18801 \\
S.E. of regression & 36289.1259 & Akaike info criterion & 23.84508902 \\
\hline Sum squared resic & $1.4999 E+12$ & Schwarz criterion & 23.8890111 \\
\hline Log likelihood & -13689.0036 & Hannan-Quinn criter. & 23.86166956 \\
\hline Durbin-Watson st & 1.82326758 & & & \\
\hline
\end{tabular}

Dependent Variable: AHORRO

Method: Least Squares

Date: 09/08/14 Time: $10: 57$

Sample: 11149

Included observations: 1149

White heteroskedasticity-consistent standard errors \& covariance

Variable Coefficient Std. Error t-Statistic Prob.

\begin{tabular}{|l|l|l|l|l|}
\hline H_UNIP & 22934.7945 & 20611.55631 & 1.112715322 & 0.26607 \\
\hline
\end{tabular}

\begin{tabular}{|l|l|l|l|l|}
\hline NUC_HJ & 5114.42421 & 1838.620656 & 2.781663629 & 0.00550 \\
\hline NUC_SHJ & 1530.6961 & 9115.88956 & 171664925 & 0.08668 \\
\hline
\end{tabular}

\begin{tabular}{|l|l|l|l|l|}
\hline NUC_SHJ & 15630.6961 & 9115.889576 & 1.714664925 & 0.08668 \\
\hline
\end{tabular}

\begin{tabular}{|l|l|l|l|l|}
\hline NUCMONOP & 1032.66596 & 781.6505636 & 1.32113506 & 0.18672 \\
\hline
\end{tabular}

\begin{tabular}{|l|l|l|l|l|}
\hline EXT_SHJ & 1302.98147 & 1078.358158 & 1.20830121 & 0.22718 \\
\hline
\end{tabular}

\begin{tabular}{|l|l|l|l|l|}
\hline EXT_CHJ & 2845.35593 & 1241.77923 & 2.291354098 & 0.02212 \\
\hline
\end{tabular}

\begin{tabular}{|l|l|l|l|l|}
\hline EXT_MONO & 63836.2766 & 59308.09068 & 1.076350223 & 0.28200 \\
\hline
\end{tabular}

\begin{tabular}{|l|r|r|r|r|}
\hline EXT_SNUC & 1733.42466 & 1275.302453 & 1.359226318 & 0.17434 \\
\hline
\end{tabular}

\begin{tabular}{|l|r|r|r|}
\hline COMPNUC & 0 & 0 & 1.00000 \\
\hline
\end{tabular}

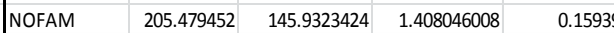

\begin{tabular}{l|l|l|l|}
\hline R-squared & 0.00922472 & Mean dependent var & 11127.8658 \\
\hline
\end{tabular}

\begin{tabular}{|l|l|l|l|}
\hline Adjusted R-sqi & 0.00139594 & S.D. dependent var & 168117.5252 \\
\hline
\end{tabular}

\begin{tabular}{|l|l|l|}
\hline S.E. of regressi 168000.143 & Akaike info criterion & 26.90998242 \\
\hline
\end{tabular}

\begin{tabular}{|l|l|l|l|}
\hline Sum squared $\mathrm{r}$ & $3.2147 \mathrm{E}+13$ & Schwarz criterion & 26.9539045 \\
\hline
\end{tabular}

\begin{tabular}{|l|l|l|}
\hline Log likelihood -15449.7849 Hannan-Quinn criter. & 26.92656295 \\
\hline
\end{tabular}

Durbin-Watsol 2.00564786

Method: Least Squares

Date: 09/08/14 Time: $10: 58$

Sample: 11149

Included observations: 1149

White heteroskedasticity-consistent standard errors \& covariance

Variable Coefficient Std. Error t-Statistic Prob.

H_UNIP 51235.3256

NUC_HJ

51235.3256

\begin{tabular}{|l|l}
11454.7829 & 4.472832537 \\
\hline
\end{tabular}

0.0000

NUC_SHJ

68796.1343

$\begin{array}{ll}3343.504134 & 17.43730146\end{array}$

\begin{tabular}{l|lll|l}
\hline EXT_SHJ & 102295.018 & 43230.30421 & 2.366280322 \\
\hline
\end{tabular}

\begin{tabular}{l|l|l|l}
\hline EXT_CHJ & 69078.7442 & 7177.329498 & 9.624574747
\end{tabular}

\begin{tabular}{l|r|r|r|}
\hline EXT_MONO & 80110.499 & 14826.65176 & 5.403141606 \\
\hline
\end{tabular}

\begin{tabular}{|l|l|l|l|}
\hline EXT_SNUC & 51588.0982 & 8981.126883 & 5.744056269 \\
\hline
\end{tabular}

\begin{tabular}{|l|l|l|l|}
\hline COMPNUC & 35253.4247 & 1396.086076 & 25.25161254 \\
\hline
\end{tabular}

\begin{tabular}{l|lll} 
NOFAM & 63390.7534 & 4693.913792 & 13.50488233
\end{tabular}

0.0000

0.0000

0.0000

0.0181

0.0000

0.0000

0.0000

0.0000

\begin{tabular}{|l|l|l|l|l|}
\hline & & \\
\hline
\end{tabular}

\begin{tabular}{|l|l|l|l|}
\hline R-squared & 0.0116647 & Mean dependent var & 61998.43059 \\
\hline
\end{tabular}

\begin{tabular}{|lll|l|}
\hline Adjusted R-sqi 0.00385521 & S.D. dependent var & 99999.29259 \\
\hline
\end{tabular}

\begin{tabular}{|l|l|l|}
\hline S.E. of regressi 99806.3475 & Akaike info criterion & 25.86851632 \\
\hline
\end{tabular}

\begin{tabular}{|lll|r|}
\hline Sum squared $r$ & $1.1346 \mathrm{E}+13$ & Schwarz criterion & 25.9124384 \\
\hline
\end{tabular} \begin{tabular}{|l|l|l|}
\hline Log likelihood -14851.4626 Hannan-Quinn criter. & 25.88509686 \\
\hline
\end{tabular}

Durbin-Watsol 1.6044337

\section{Fuente: elaboración propia}




\section{Anexo 2. Estimaciones Gastos en bienes y servicios. Cauca Rural. Ciclo de Vida}

\begin{tabular}{|c|c|c|c|c|}
\hline \multicolumn{5}{|c|}{ Dependent Variable: ALIM } \\
\hline \multicolumn{5}{|c|}{ Method: Least Squares } \\
\hline \multicolumn{5}{|c|}{ Date: 09/08/14 Time: $10: 58$} \\
\hline \multicolumn{5}{|c|}{ Sample: 11149} \\
\hline \multicolumn{5}{|c|}{ Included observations: 1149} \\
\hline \multicolumn{5}{|c|}{ White heteroskedasticity-consistent standard errors \& covariance } \\
\hline Variable & Coefficient & Std. Error & t-Statistic & Prob. \\
\hline HOGINI & 247475.165 & 10603.44 & 23.3391483 & 0.00000 \\
\hline HOGEXP & 275692.982 & 16695.5 & 16.5130119 & 0.00000 \\
\hline HOGCON & 268430.568 & 12107.99 & 22.1696997 & 0.00000 \\
\hline PAREJOV & 279535.714 & 49941.66 & 5.5972457 & 0.00000 \\
\hline PARMAY & 212814.286 & 16537.58 & 12.868529 & 0.00000 \\
\hline R-squared & 0.03852331 & \multicolumn{2}{|c|}{ Mean dependent var } & 239706.3073 \\
\hline Adjusted R-squ & 0.03600765 & \multicolumn{2}{|c|}{ S.D. dependent var } & 187541.0133 \\
\hline S.E. of regressic & 221113.68 & \multicolumn{2}{|c|}{ Akaike info criterion } & 27.45508365 \\
\hline Sum squared re & $5.5932 E+13$ & \multicolumn{2}{|c|}{ Schwarz criterion } & 27.4770447 \\
\hline Log likelihood & -15767.9456 & \multicolumn{2}{|c|}{ Hannan-Quinn criter. } & 27.46337392 \\
\hline Durbin-Watson & 1.41126261 & & & \\
\hline
\end{tabular}

Dependent Variable: SAL

Method: Least Squares

Date: 09/08/14 Time: $10: 58$

Sample: 11149

Included observations: 1149

White heteroskedasticity-consistent standard errors \& covariance

\begin{tabular}{|l|r|r|r|r|}
\hline Variable & Coefficient & Std. Error & t-Statistic & Prob. \\
\hline HOGINI & 34900.5777 & 6372.99 & 5.47632674 & 0.0000 \\
\hline HOGEXP & 46858.1629 & 10452.61 & 4.48291709 & 0.0000 \\
\hline HOGCON & 40652.3338 & 5971.703 & 6.80749395 & 0.0000 \\
\hline PAREJOV & 59784.1986 & 26563.55 & 2.25061068 & 0.0246 \\
\hline PARMAY & 85025.9699 & 37196.9 & 2.28583473 & 0.0224 \\
\hline & & & & \\
\hline R-squared & 0.03503031 & Mean dependent var & 41538.1261 \\
\hline Adjusted R-squ & 0.03370118 & S.D. dependent var & 150008.6831 \\
\hline S.E. of regressic & 150533.679 & Akaike info criterion & 26.68610341 \\
\hline Sum squared re & $2.5923 E+13$ & Schwarz criterion & 26.70806445 \\
\hline Log likelihood & -15326.1664 & Hannan-Quinn criter. & 26.69439368 \\
\hline Durbin-Watson & 1.86454864 & & & \\
\hline
\end{tabular}

\begin{tabular}{|l|l|l|l|r|}
\hline $\begin{array}{l}\text { Dependent Variable: EDUC } \\
\text { Method: Least Squares } \\
\text { Date: 09/08/14 Time: } 10: 58\end{array}$ & & & \\
Sample: 11149 & & & \\
Included observations: 1149 & & & \\
White heteroskedasticity-consistent standard errors \& covariance
\end{tabular}

\begin{tabular}{|c|c|c|c|c|}
\hline \multicolumn{5}{|c|}{ Dependent Variable: TRANS } \\
\hline \multicolumn{5}{|c|}{ Method: Least Squares } \\
\hline \multicolumn{5}{|c|}{ Date:09/08/14 Time: 10:58 } \\
\hline \multicolumn{5}{|c|}{ Sample:11149 } \\
\hline \multicolumn{5}{|c|}{ Included observations: 1149} \\
\hline \multicolumn{5}{|c|}{ White heteroskedasticity-consistent standard errors \& covariance } \\
\hline Variable & Coefficient & Std. Error & t-Statistic & Prob. \\
\hline HOGINI & 28164.49397 & 5038.638 & 5.58970373 & 0.0000 \\
\hline HOGEXP & 35004.77526 & 7310.963 & 4.78798425 & 0.0000 \\
\hline HOGCON & 22480.31374 & 3242.771 & 6.93243987 & 0.0000 \\
\hline PAREJOV & 51811.8768 & 28239.29 & 1.8347446 & 0.0668 \\
\hline PARMAY & 15122.00683 & 2551.211 & 5.92738364 & 0.0000 \\
\hline R-squared & 0.015557014 & \multicolumn{2}{|c|}{ Mean dependent var } & 24756.81354 \\
\hline Adjusted R-squ & 0.0151079 & \multicolumn{2}{|c|}{ S.D. dependent var } & 74126.69441 \\
\hline S.E. of regressi & 74831.54649 & \multicolumn{2}{|c|}{ Akaike info criterion } & 25.28820882 \\
\hline Sum squared $\mathrm{rt}$ & $6.40613 \mathrm{E}+12$ & \multicolumn{2}{|c|}{ Schwarz criterion } & 25.31016986 \\
\hline Log likelihood & -14523.076 & \multicolumn{2}{|c|}{ Hannan-Quinn criter. } & 25.29649909 \\
\hline Durbin-Watsor & 1.775267539 & & & \\
\hline
\end{tabular}




\section{Anexo 2. Estimaciones Gastos en bienes y servicios. Cauca Rural. Ciclo de Vida} (Continuación)

\begin{tabular}{|c|c|c|c|c|}
\hline \multicolumn{5}{|c|}{ Dependent Variable: GASPER } \\
\hline \multicolumn{5}{|c|}{ Method: Least Squares } \\
\hline \multicolumn{5}{|c|}{ Date: 09/08/14 Time: $10: 58$} \\
\hline \multicolumn{5}{|c|}{ Sample: 11149} \\
\hline \multicolumn{5}{|c|}{ Included observations: 1149} \\
\hline \multicolumn{5}{|c|}{ White heteroskedasticity-consistent standard errors \& covariance } \\
\hline Variable & Coefficient & Std. Error & t-Statistic & Prob. \\
\hline HOGINI & 29309.6875 & 51756.5676 & 16.685773 & 0.000 \\
\hline HOGEXP & 27936.4931 & $1 \quad 1920.863$ & 14.5437196 & 0.000 \\
\hline HOGCON & 27538.736 & 62013.0489 & 13.6801129 & 0.000 \\
\hline PAREJOV & 32452.7048 & 86163.6464 & 5.26517948 & 0.000 \\
\hline PARMAY & 19350.2233 & 31994.0878 & 9.70379717 & 0.000 \\
\hline R-squared & 0.02718143 & \multicolumn{2}{|c|}{ Mean dependent var } & 25452.47017 \\
\hline Adjusted R-s & 0.02560514 & \multicolumn{2}{|c|}{ S.D. dependent var } & 26572.76645 \\
\hline S.E. of regres & 29303.0437 & \multicolumn{2}{|c|}{ Akaike info criterion } & 23.41311252 \\
\hline Sum squarec & $9.8232 E+11$ & \multicolumn{2}{|c|}{ Schwarz criterion } & 23.43507356 \\
\hline Log likelihoo & -13445.8331 & \multicolumn{2}{|c|}{ Hannan-Quinn criter. } & 23.42140279 \\
\hline Durbin-Wats & 1.54970232 & & & \\
\hline
\end{tabular}

\begin{tabular}{|c|c|c|c|c|}
\hline \multicolumn{3}{|c|}{ Dependent Variable: AHORRO } & & \\
\hline \multicolumn{5}{|c|}{ Method: Least Squares } \\
\hline \multicolumn{5}{|c|}{ Date: 09/08/14 Time: 10:58 } \\
\hline \multicolumn{5}{|c|}{ Sample: 11149} \\
\hline \multicolumn{5}{|c|}{ Included observations: 1149} \\
\hline \multicolumn{5}{|c|}{ White heteroskedasticity-consistent standard errors \& covariance } \\
\hline Variable & Coefficient & Std. Error & t-Statistic & Prob. \\
\hline HOGINI & 1600.2632 & 814.063409 & 1.96577218 & 0.050 \\
\hline HOGEXP & 10056.7171 & 4639.35378 & 2.16769783 & 0.030 \\
\hline HOGCON & 3201.53137 & 1168.99594 & 4. 2.73870189 & 0.006 \\
\hline PAREJOV & 34441.2916 & 29070.2281 & 1.18476166 & 0.236 \\
\hline PARMAY & 5826.22309 & 3306.87788 & 1.76185009 & 0.078 \\
\hline R-squared & 0.00962814 & \multicolumn{2}{|c|}{ Mean dependent var } & 11127.8658 \\
\hline Adjusted R-s & s -0.00613389 & \multicolumn{2}{|c|}{ S.D. dependent var } & 168117.5252 \\
\hline S.E. of regres & 168632.339 & \multicolumn{2}{|c|}{ Akaike info criterion } & 26.91317141 \\
\hline Sum squarec & c $3.2532 \mathrm{E}+13$ & \multicolumn{2}{|c|}{ Schwarz criterion } & 26.93513246 \\
\hline Log likelihoc & c -15456.617 & \multicolumn{2}{|c|}{ Hannan-Quinn criter. } & 26.92146168 \\
\hline Durbin-Wats & is 2.00509319 & & & \\
\hline
\end{tabular}

\begin{tabular}{|c|c|c|c|c|}
\hline \multicolumn{3}{|c|}{ Dependent Variable: VEST } & & \\
\hline \multicolumn{3}{|c|}{ Method: Least Squares } & & \\
\hline \multicolumn{3}{|c|}{ Date: 09/08/14 Time: 10:59 } & & \\
\hline \multicolumn{2}{|c|}{ Sample: 11149} & & & \\
\hline \multicolumn{3}{|c|}{ Included observations: 1149} & & \\
\hline \multicolumn{5}{|c|}{ White heteroskedasticity-consistent standard errors \& covariance } \\
\hline Variable & Coefficient & Std. Error & t-Statistic & Prob. \\
\hline HOGINI & 23332.0204 & t. 3239.8757 & 7.20151711 & 0.00000 \\
\hline HOGEXP & 20305.4581 & 3142.2972 & 6.46197877 & 0.00000 \\
\hline HOGCON & 13407.5691 & 1773.5866 & 7.55957954 & 0.00000 \\
\hline PAREJOV & 15345.2381 & 4740.8024 & 3.23684405 & 0.00124 \\
\hline PARMAY & 10346.0317 & 3076.2544 & 3.36319123 & 0.00080 \\
\hline R-squared & 0.04071626 & \multicolumn{2}{|c|}{ Mean dependent var } & 16584.07253 \\
\hline Adjusted R-s & s 0.03835513 & \multicolumn{2}{|c|}{ S.D. dependent var } & 36374.18801 \\
\hline S.E. of regres & 37172.1267 & \multicolumn{2}{|c|}{ Akaike info criterion } & 23.88884814 \\
\hline Sum squarec & c $1.5807 \mathrm{E}+12$ & \multicolumn{2}{|c|}{ Schwarz criterion } & 23.91080918 \\
\hline Log likelihoo & o - 13719.1433 & \multicolumn{2}{|c|}{ Hannan-Quinn criter. } & 23.89713841 \\
\hline Durbin-Wats & s 1.78647275 & & & \\
\hline
\end{tabular}

\begin{tabular}{|c|c|c|c|c|}
\hline \multicolumn{5}{|c|}{ Dependent Variable: VIV } \\
\hline \multicolumn{5}{|c|}{ Method: Least Squares } \\
\hline \multicolumn{5}{|c|}{ Date: 09/08/14 Time: $11: 45$} \\
\hline \multicolumn{5}{|c|}{ Sample: 11149} \\
\hline \multicolumn{5}{|c|}{ Included observations: 1149} \\
\hline \multicolumn{5}{|c|}{ White heteroskedasticity-consistent standard errors \& covariance } \\
\hline Variable & Coefficient & Std. Error & t-Statistic & Prob. \\
\hline HOGINI & 55781.4943 & 4548.1637 & 12.2646189 & 0.00000 \\
\hline HOGEXP & 69314.2679 & 6504.08399 & 10.6570376 & 0.00000 \\
\hline HOGCON & 60630.9046 & 5374.46221 & 11.281297 & 0.00000 \\
\hline PAREJOV & 119538.386 & 52625.9218 & 2.27147348 & 0.02330 \\
\hline PARMAY & 65811.392 & 7790.93659 & 8.44717336 & 0.00000 \\
\hline R-squared & 0.01032868 & \multicolumn{2}{|c|}{ Mean dependent var } & 61998.43059 \\
\hline Adjusted R-s & 0.01001445 & \multicolumn{2}{|c|}{ S.D. dependent var } & 99999.29259 \\
\hline S.E. of regres & 105220.188 & \multicolumn{2}{|c|}{ Akaike info criterion } & 25.9698401 \\
\hline Sum squarec & $1.2666 \mathrm{E}+13$ & \multicolumn{2}{|c|}{ Schwarz criterion } & 25.99180114 \\
\hline Log likelihoc & -14914.6731 & \multicolumn{2}{|c|}{ Hannan-Quinn criter. } & 25.97813037 \\
\hline Durbin-Wats & 1.56472264 & & & \\
\hline
\end{tabular}

Fuente: elaboración propia 


\section{Anexo 3. Estimaciones Gastos en bienes y servicios. Cauca Urbano. Tipología del Hogar}

\begin{tabular}{|c|c|c|c|c|}
\hline \multicolumn{5}{|c|}{ Dependent Variable: ALIM } \\
\hline \multicolumn{5}{|c|}{ Method: Least Squares } \\
\hline \multicolumn{5}{|c|}{ Date: 09/08/14 Time: $14: 45$} \\
\hline \multicolumn{5}{|c|}{ Sample: 11141} \\
\hline \multicolumn{5}{|c|}{ Included observations: 1141} \\
\hline \multicolumn{5}{|c|}{ White heteroskedasticity-consistent standard errors \& covariance } \\
\hline Variable & Coefficient & Std. Error & t-Statistic & Prob. \\
\hline H_UNIP & 261242.659 & 20392.5448 & 12.8106944 & 0.0000 \\
\hline NUC_HJ & 456680.702 & 21584.9578 & 21.157359 & 0.0000 \\
\hline NUC_SHJ & 441640.11 & 35364.1057 & 12.4883721 & 0.0000 \\
\hline NUCMONOP & 353765.855 & 18813.667 & 18.8036631 & 0.0000 \\
\hline EXT_SHJ & 419820 & 66560.0232 & 6.30738963 & 0.0000 \\
\hline EXT_CHJ & 482442.918 & 37356.5743 & 12.9145385 & 0.0000 \\
\hline EXT_MONO & 429568.758 & 32294.7608 & 13.3014999 & 0.0000 \\
\hline EXT_SNUC & 362277.108 & 35900.5948 & 10.0911172 & 0.0000 \\
\hline COMPNUC & 808775.51 & 144184.616 & 5.60930516 & 0.0000 \\
\hline COMPUEXT & 1094857.14 & 335537.62 & 3.26299371 & 0.0011 \\
\hline COMPSINUC & 704271.429 & 141415.025 & 4.98017397 & 0.0000 \\
\hline R-squared & 0.06805806 & \multicolumn{2}{|c|}{ Mean dependent var } & 412544 \\
\hline Adjusted R-squared & 0.05981079 & \multicolumn{2}{|c|}{ S.D. dependent var } & 364096.2 \\
\hline S.E. of regression & 353039.888 & \multicolumn{2}{|c|}{ Akaike info criterion } & 28.39614 \\
\hline Sum squared resid & $1.4084 \mathrm{E}+14$ & \multicolumn{2}{|c|}{ Schwarz criterion } & 28.44473 \\
\hline Log likelihood & -16188.9999 & \multicolumn{2}{|c|}{ Hannan-Quinn criter. } & 28.41449 \\
\hline Durbin-Watson stat & 1.40568616 & & & \\
\hline
\end{tabular}

\begin{tabular}{|c|c|c|c|c|}
\hline \multicolumn{5}{|c|}{ Dependent Variable: EDUC } \\
\hline \multicolumn{5}{|c|}{ Method: Least Squares } \\
\hline \multicolumn{5}{|c|}{ Date: 09/08/14 Time: $14: 42$} \\
\hline \multicolumn{5}{|c|}{ Sample: 11141} \\
\hline \multicolumn{5}{|c|}{ Included observations: 1141} \\
\hline \multicolumn{5}{|c|}{ White heteroskedasticity-consistent standard errors \& covarianc } \\
\hline Variable & Coefficient & Std. Error & \multicolumn{2}{|c|}{ t-Statis Prob. } \\
\hline H_UNIP & 4261.01667 & 1417.94782 & 3.005 & 0.00271 \\
\hline NUC_HJ & 71248.95794 & 7231.70078 & 9.852 & 0.00000 \\
\hline NUC_SHJ & 4991.043204 & 4424.00129 & 1.128 & 0.25949 \\
\hline NUCMONOP & 42211.38229 & 6093.20723 & 6.928 & 0.00000 \\
\hline EXT_SHJ & 33005.64384 & 11018.5513 & 2.995 & 0.00280 \\
\hline EXT_CHJ & 95722.05246 & 14343.1886 & 6.674 & 0.00000 \\
\hline EXT_MONO & 77584.23492 & 13490.9649 & 5.751 & 0.00000 \\
\hline EXT_SNUC & 47474.45271 & 12365.091 & 3.839 & 0.00013 \\
\hline COMPNUC & 482458.501 & 128306.119 & 3.76 & 0.00018 \\
\hline COMPUEXT & 177447.4886 & 82657.9511 & 2.147 & 0.03202 \\
\hline COMPSINUC & 102302.2831 & 50996.4934 & 2.006 & 0.04509 \\
\hline R-squared & 0.168564223 & \multicolumn{2}{|c|}{ Mean dependent } & 59154.65095 \\
\hline Adjusted R-sq & 0.161206384 & \multicolumn{2}{|c|}{ S.D. dependent va } & 137868.4422 \\
\hline S.E. of regress & 126267.7456 & \multicolumn{2}{|c|}{ Akaike info criteri } & 26.33979075 \\
\hline Sum squared & $1.80162 \mathrm{E}+13$ & \multicolumn{2}{|c|}{ Schwarz criterion } & 26.38837644 \\
\hline Log likelihooc & -15015.85063 & \multicolumn{2}{|c|}{ Hannan-Quinn crit } & 26.3581381 \\
\hline Durbin-Watsc & 1.839618754 & & & \\
\hline
\end{tabular}

Dependent Variable: SAL

Method: Least Squares

Date: 09/08/14 Time: $14: 43$

Sample: 11141

Included observations: 1141

White heteroskedasticity-consistent standard errors \& covariance

Variable Coefficient Std. Error t-Statistic Prob.

\begin{tabular}{l|l|l|l}
\hline H_UNIP & 67038.2831 & 14098.35 & 4.75504458 \\
\hline
\end{tabular}

\begin{tabular}{|l|l|l|l|}
\hline NUC_HJ & 109895.598 & 12613.1572 & 8.71277476 \\
\hline
\end{tabular}

NUC_SHJ

NUCMONOP

EXT_SHJ

EXT_CHJ

EXT_MONO

EXT_SNUC

COMPNUC

COMPUEXT

COMPSINUC

\begin{tabular}{|l|l|l|l|}
\hline 109895.598 & 12613.1572 & 8.71277476 \\
\hline 180030.311 & 42505.9664 & 4.23541273 \\
\hline
\end{tabular}

\begin{tabular}{|l|l|l|l|}
92724.132 & 16617.2111 & 5.58000566
\end{tabular}

$\begin{array}{lll}85162.1233 & 22411.8524 & 3.7998699\end{array}$

$\begin{array}{llll}211622.829 & 29086.2266 & 7.27570585\end{array}$

\begin{tabular}{|l|l|l|l|}
154361.866 & 38518.2537 & 4.00749908
\end{tabular}

$\begin{array}{llll}97806.3248 & 20651.3734 & 4.73606878\end{array}$

$\begin{array}{llll}393914.962 & 108800.14 & 3.62053728\end{array}$

\begin{tabular}{|l|l|l|}
409314.356 & 40762.6018 & 10.0414188
\end{tabular}

$\begin{array}{llll}260414.444 & 73274.7112 & 3.55394706\end{array}$

R-squared

0.04318845 Mean dependent var

Adjusted R-squared

S.E. of regression

Sum squared resid

Log likelihood

0.03472109 S.D. dependent var

269841.824 Akaike info criterion

$8.2281 \mathrm{E}+13$ Schwarz criterion

-15882.3618 Hannan-Quinn criter.

1.64962828
Dependent Variable: TRANS

Method: Least Squares

Date: 09/08/14 Time: 14:43

Sample: 11141

Included observations: 1141

White heteroskedasticity-consistent standard errors \& covariance

Variable Coefficient Std. Error t-Statis Prob.

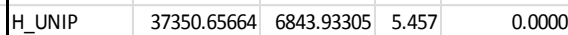

\begin{tabular}{l|llll} 
NUC_HJ & 74399.25962 & 8900.54373 & 8.359 & 0.0000
\end{tabular}

\begin{tabular}{|l|l|l|l|l|}
\hline NUC_SHJ & 75675.78119 & 14281.3218 & 5.299 & 0.0000 \\
\hline
\end{tabular}

\begin{tabular}{|l|l|l|l|l|}
\hline NUCMONOP & 29549.75652 & 5439.97776 & 5.432 & 0.0000 \\
\hline
\end{tabular}

\begin{tabular}{l|lllll|} 
EXT_SHJ & 48239.13894 & 25367.5893 & 1.902 & 0.0575 \\
\hline
\end{tabular}

\begin{tabular}{|l|r|rrr|}
\hline EXT_CHJ & 87001.44449 & 17367.9896 & 5.009 & 0.0000 \\
\hline
\end{tabular}

\begin{tabular}{|l|r|r|r|r|}
\hline EXT_MONO & 30708.64988 & 8500.78015 & 3.612 & 0.0003 \\
\hline
\end{tabular}

\begin{tabular}{|l|l|l|l|l|}
\hline EXT_SNUC & 47145.31708 & 10875.335 & 4.335 & 0.0000 \\
\hline
\end{tabular}

\begin{tabular}{|l|l|l|l|l|}
\hline COMPNUC & 212066.6689 & 34077.4794 & 6.223 & 0.0000 \\
\hline
\end{tabular}

\begin{tabular}{|l|r|r|r|r|}
\hline COMPUEXT & 336066.5362 & 216734.761 & 1.551 & 0.1213 \\
\hline
\end{tabular}

$\begin{array}{llllll}\text { COMPSINUC } & 242194.7525 & 95020.102 & 2.549 & 0.0109\end{array}$

\begin{tabular}{|l|l|l|l}
\hline R-squared & 0.060143907 & Mean dependent ' 60875.52988
\end{tabular}

$\begin{array}{llll}\text { Adjusted R-sc } & 0.051826596 & \text { S.D. dependent va } 142912.4456\end{array}$

S.E. of regress 139159.8448 Akaike info criteri 26.53422799

\begin{tabular}{l|l|l|l} 
Sum squared & $2.1883 \mathrm{E}+13$ & Schwarz criterion 26.58281367
\end{tabular}

Log likelihooc -15126.77707 Hannan-Quinn crit 26.55257533

Durbin-Watsc 1.796095815 


\section{Anexo 3. Estimaciones Gastos en bienes y servicios. Cauca Urbano. Tipología del Hogar. (Continuación)}

\begin{tabular}{|c|c|c|c|c|}
\hline \multicolumn{5}{|l|}{ Depe } \\
\hline \multicolumn{5}{|l|}{ Method: Least Squares } \\
\hline \multicolumn{5}{|c|}{ Date: 09/08/14 Time: $14: 43$} \\
\hline \multicolumn{5}{|c|}{ Sample: 11141} \\
\hline \multicolumn{5}{|c|}{ Included observations: 1141} \\
\hline \multicolumn{5}{|c|}{ White heteroskedasticity-consistent standard errors \& covariance } \\
\hline Variable & \multicolumn{2}{|c|}{ Coefficient Std. Error } & t-Statistic & Prob. \\
\hline H_UNIP & 56161.624 & 7075.04145 & 7.9379923 & 0.00000 \\
\hline NUC_HJ & 70059.047 & 5737.00402 & 12.211783 & 0.00000 \\
\hline NUC_SHJ & 73496.983 & 11064.2013 & 6.6427735 & 0.00000 \\
\hline NUCMONOP & 63813.243 & 8761.18991 & 7.2836274 & 0.00000 \\
\hline EXT_SHJ & 32798.886 & 5634.37061 & 5.8212156 & 0.00000 \\
\hline EXT_CHJ & 83839.757 & 14408.0426 & 5.8189554 & 0.00000 \\
\hline EXT_MONO & 70574.258 & 10824.2118 & 6.5200367 & 0.00000 \\
\hline EXT_SNUC & 69177.279 & 12494.3216 & 5.5366975 & 0.00000 \\
\hline COMPNUC & 253486.1 & 112318.09 & 2.2568591 & 0.02421 \\
\hline COMPUEXT & 447055.12 & 251990.881 & 1.7740925 & 0.07632 \\
\hline COMPSINUC & 158056.27 & 44125.5024 & 3.581971 & 0.00036 \\
\hline R-squared & 0.0558541 & \multicolumn{2}{|c|}{ Mean dependent var } & 72154.848 \\
\hline Adjusted R-squared & 0.0474988 & \multicolumn{2}{|c|}{ S.D. dependent var } & 128760.52 \\
\hline S.E. of regression & 125665.33 & \multicolumn{2}{|c|}{ Akaike info criterion } & 26.330226 \\
\hline Sum squared resid & $1.784 E+13$ & \multicolumn{2}{|c|}{ Schwarz criterion } & 26.378812 \\
\hline Log likelihood & -15010.394 & \multicolumn{2}{|c|}{ Hannan-Quinn criter. } & 26.348573 \\
\hline Durbin-Watson stat & 1.4541943 & & & \\
\hline
\end{tabular}

Dependent Variable: VEST

Method: Least Squares

Date: 09/08/14 Time: 14:43

Sample: 11141

Included observations: 1141

White heteroskedasticity-consistent standard errors \& covariance

\begin{tabular}{|c|c|c|c|c|}
\hline Variable & Coefficient & Std. Error & t-Statistic & Prob. \\
\hline H_UNIP & 23385.542 & 4664.44965 & 5.0135694 & 0.00000 \\
\hline NUC_HJ & 42746.596 & 4198.60127 & 10.181152 & 0.00000 \\
\hline NUC_SHJ & 40423.077 & 7656.34004 & 5.2796867 & 0.00000 \\
\hline NUCMONOP & 40652.132 & 8705.15864 & 4.6698898 & 0.00000 \\
\hline EXT_SHJ & 8466.6667 & 5922.43321 & 1.4295926 & 0.15311 \\
\hline EXT_CHJ & 43217.494 & 10703.8086 & 4.037581 & 0.00006 \\
\hline EXT_MONO & 31255.452 & 4625.68947 & 6.7569282 & 0.00000 \\
\hline EXT_SNUC & 43807.229 & 10865.3532 & 4.0318274 & 0.00006 \\
\hline COMPNUC & 120714.29 & 47610.6227 & 2.5354486 & 0.01136 \\
\hline COMPUEXT & 118888.89 & 49083.9573 & 2.4221537 & 0.01559 \\
\hline COMPSINUC & 90370.37 & 24816.673 & 3.6415184 & 0.00028 \\
\hline R-squared & 0.0235196 & \multicolumn{2}{|c|}{ Mean dependent var } & 39256.941 \\
\hline Adjusted R-squared & 0.0148782 & \multicolumn{2}{|c|}{ S.D. dependent var } & 90144.013 \\
\hline S.E. of regression & 89470.911 & \multicolumn{2}{|c|}{ Akaike info criterion } & 25.650809 \\
\hline Sum squared resid & $9.046 \mathrm{E}+12$ & \multicolumn{2}{|c|}{ Schwarz criterion } & 25.699394 \\
\hline Log likelihood & -14622.786 & \multicolumn{2}{|c|}{ Hannan-Quinn criter. } & 25.669156 \\
\hline Durbin-Watson stat & 1.7367563 & & & \\
\hline
\end{tabular}

\begin{tabular}{|c|c|c|c|c|}
\hline \multicolumn{5}{|c|}{ Dependent Variable: AHORRO } \\
\hline \multicolumn{5}{|c|}{ Method: Least Squares } \\
\hline \multicolumn{5}{|c|}{ Date: 09/08/14 Time: $14: 43$} \\
\hline \multicolumn{5}{|c|}{ Sample: 11141} \\
\hline \multicolumn{5}{|c|}{ Included observations: 1141} \\
\hline \multicolumn{5}{|c|}{ White heteroskedasticity-consistent standard errors \& covariance } \\
\hline Variable & \multicolumn{2}{|c|}{ Coefficien Std. Error } & t-Statistic & Prob. \\
\hline H_UNIP & 96378.78 & 79524.7781 & 1.21193391 & 0.2258 \\
\hline NUC_HJ & 42755.11 & 33958.256 & 1.25904896 & 0.2083 \\
\hline NUC_SHJ & 76839.83 & 73618.508 & 1.04375698 & 0.2968 \\
\hline NUCMONOP & 4925.773 & 4085.66132 & 1.20562429 & 0.2282 \\
\hline EXT_SHJ & 0 & 0 & & 1.0000 \\
\hline EXT_CHJ & 12688.49 & 11677.9962 & 1.08652939 & 0.2775 \\
\hline EXT_MONO & 794.879 & 336.342122 & 2.36330499 & 0.0183 \\
\hline EXT_SNUC & 1582.439 & 846.596159 & 1.86917851 & 0.0619 \\
\hline COMPNUC & 114833.7 & 95855.6757 & 1.19798498 & 0.2312 \\
\hline COMPUEXT & 1150.685 & 944.092173 & 3. 1.2188269 & 0.2232 \\
\hline COMPSINUC & 5684.932 & 4251.12955 & 1.33727553 & 0.1814 \\
\hline R-squared & 0.003932 & \multicolumn{2}{|c|}{ Mean dependent var } & 36046.995 \\
\hline \multicolumn{2}{|c|}{ Adjusted R-squared -0.004883} & \multicolumn{2}{|c|}{ S.D. dependent var } & 550235.65 \\
\hline S.E. of regression & 551577.3 & \multicolumn{2}{|c|}{ Akaike info criterion } & 29.288546 \\
\hline Sum squared resid & $3.44 E+14$ & \multicolumn{2}{|c|}{ Schwarz criterion } & 29.337131 \\
\hline Log likelihood & -16698.12 & \multicolumn{2}{|c|}{ Hannan-Quinn criter. } & 29.306893 \\
\hline Durbin-Watson stat & 2.002875 & & & \\
\hline
\end{tabular}

Dependent Variable: VIV

Method: Least Squares

Date: 09/08/14 Time: $14: 43$

Sample: 11141

Included observations: 1141

White heteroskedasticity-consistent standard errors \& covariance

Variable CoefficienStd. Error t-Statistic Prob.

\begin{tabular}{l|l|l|l}
\hline H UNIP & 207168.7 & 19631.9957 & 10.5526068
\end{tabular}

\begin{tabular}{l|l|l|l|l}
\hline NUC_HJ & 266194.1 & 17357.5315 & 15.3359445 \\
\hline
\end{tabular}

\begin{tabular}{l|l|l|l|l}
\hline NUC_SHJ & 273740.3 & 36133.805 & 7.57573838 \\
\hline
\end{tabular}

\begin{tabular}{l|l|l|l}
\hline NUCMONOP & 214427.5 & 19728.2732 & 10.8690446
\end{tabular}

\begin{tabular}{l|l|l|l|l}
\hline EXT_SHJ & 149661.5 & 24102.4918 & 6.20937748 \\
\hline
\end{tabular}

\begin{tabular}{l|l|l|l|l}
\hline EXT_CHJ & 269474.1 & 28156.8043 & 9.57047845 \\
\hline
\end{tabular}

\begin{tabular}{l|l|l|l}
\hline EXT_MONO & 211440.1 & 22688.2494 & 9.31936688
\end{tabular}

\begin{tabular}{l|l|l|l}
\hline EXT_SNUC & 256454.1 & 39146.634 & 6.5511155 \\
\hline
\end{tabular}

\begin{tabular}{l|l|l|l}
\hline COMPNUC & 587922.3 & 72091.2522 & 8.15525117
\end{tabular}

\begin{tabular}{|l|l|l|l|l|}
\hline COMPUEXT & 968209.5 & 140377.321 & 6.89719347 \\
\hline
\end{tabular}

\begin{tabular}{|l|r|r|r|r|}
\hline COMPSINUC & 416340.4 & 102680.132 & 4.05473143 \\
\hline
\end{tabular}

\begin{tabular}{|l|l|l|}
\hline R-squared & 0.042697 & Mean dependent var \\
\hline
\end{tabular}

$\begin{array}{lll}\text { Adjusted R-squared } 0.034225 & \text { S.D. dependent var }\end{array}$

\begin{tabular}{ll|l|l|}
\hline S.E. of regression 296116.3 & Akaike info criterion 28.044486 \\
\hline
\end{tabular}

\begin{tabular}{|l|l|l|l|}
\hline Sum squared resid & $9.91 \mathrm{E}+13$ & Schwarz criterion & 28.093072 \\
\hline
\end{tabular}

\begin{tabular}{|l|l|l|l|}
\hline Log likelihood & -15988.38 & Hannan-Quinn criter. & 28.062834 \\
\hline
\end{tabular}

Fuente: elaboración propia 


\section{Anexo 4. Estimaciones Gastos en bienes y servicios. Cauca Urbano. Ciclo de Vida}

\begin{tabular}{|c|c|c|c|c|}
\hline \multicolumn{5}{|c|}{ Dependent Variable: ALIM } \\
\hline \multicolumn{5}{|c|}{ Method: Least Squares } \\
\hline \multicolumn{5}{|c|}{ Date: 09/08/14 Time: $14: 44$} \\
\hline \multicolumn{5}{|c|}{ Sample: 11141} \\
\hline \multicolumn{5}{|c|}{ Included observations: 1141} \\
\hline \multicolumn{5}{|c|}{ White heteroskedasticity-consistent standard errors \& covariance } \\
\hline Variable & Coefficient & Std. Error & t-Statistic & Prob. \\
\hline HOGINI & 388556.5889 & 22213.17485 & 17.4921681 & 0.0000 \\
\hline HOGEXP & 502732.5417 & 40722.83393 & 12.3452249 & 0.0000 \\
\hline HOGCON & 525561.5801 & 31102.11765 & 16.8979356 & 0.0000 \\
\hline PAREJOV & 463440 & 66106.52835 & 7.01050277 & 0.0000 \\
\hline PARMAY & 424990.9584 & 34942.99091 & 12.1624093 & 0.0000 \\
\hline R-squared & 0.388720425 & \multicolumn{2}{|c|}{ Mean dependent var } & 412543.999 \\
\hline Adjusted R-squ & 0.373610286 & \multicolumn{2}{|c|}{ S.D. dependent var } & 364096.199 \\
\hline S.E. of regressic & 429820.1944 & \multicolumn{2}{|c|}{ Akaike info criterion } & 28.7844941 \\
\hline Sum squared re & $2.09871 E+14$ & \multicolumn{2}{|c|}{ Schwarz criterion } & 28.8065785 \\
\hline Log likelihood & -16416.55386 & \multicolumn{2}{|c|}{ Hannan-Quinn criter. } & 28.7928338 \\
\hline Durbin-Watson & 1.311507929 & & & \\
\hline
\end{tabular}

Dependent Variable: SAL

Method: Least Squares

Date: 09/08/14 Time: 14:41

Sample: 11141

Included observations: 1141

White heteroskedasticity-consistent standard errors \& covariance

\begin{tabular}{|l|r|l|r|r|}
\hline Variable & Coefficient & Std. Error & t-Statistic & Prob. \\
\hline HOGINI & 101660.1348 & 14210.58502 & 7.15383179 & 0.0000 \\
\hline HOGEXP & 136340.7483 & 21270.78691 & 6.40976513 & 0.0000 \\
\hline HOGCON & 191246.8436 & 24661.15915 & 7.75498193 & 0.0000 \\
\hline PAREJOV & 83220.37753 & 18419.60841 & 4.51803185 & 0.0000 \\
\hline PARMAY & 182903.5915 & 42090.19219 & 4.34551571 & 0.0000 \\
\hline & & & & \\
\hline R-squared & 0.044819471 & Mean dependent var & 126622.755 \\
\hline Adjusted R-squ & 0.042498413 & S.D. dependent var & 274652.057 \\
\hline S.E. of regressii & 281233.3009 & Akaike info criterion & 27.9361293 \\
\hline Sum squared re & 8.98487 E+13 & Schwarz criterion & 27.9582137 \\
\hline Log likelihood & -15932.56175 & Hannan-Quinn criter. & 27.944469 \\
\hline Durbin-Watson & 1.588871164 & & & \\
\hline
\end{tabular}

\begin{tabular}{|c|c|c|c|c|}
\hline \multicolumn{5}{|c|}{ Dependent Variable: EDUC } \\
\hline \multicolumn{5}{|c|}{ Method: Least Squares } \\
\hline \multicolumn{5}{|c|}{ Date: 09/08/14 Time: $14: 40$} \\
\hline \multicolumn{5}{|c|}{ Sample: 11141} \\
\hline \multicolumn{5}{|c|}{ Included observations: 1141} \\
\hline \multicolumn{5}{|c|}{ White heteroskedasticity-consistent standard errors \& covariance } \\
\hline Variable & Coefficient & Std. Error & t-Statistic & Prob. \\
\hline HOGINI & 80878.8079 & 13873.6463 & 5.829672035 & 0.00000 \\
\hline HOGEXP & 116808.131 & 17421.7561 & 6.704727728 & 0.00000 \\
\hline HOGCON & 77136.7551 & 10370.3346 & 7.438212725 & 0.00000 \\
\hline PAREJOV & 16537.5342 & 13552.4289 & 1.220263492 & 0.22262 \\
\hline PARMAY & 10139.2925 & 3868.81708 & 2.620773307 & 0.00889 \\
\hline R-squared & 0.12145807 & \multicolumn{2}{|c|}{ Mean dependent var } & 59154.65095 \\
\hline Adjusted R-squ: & 0.10866745 & \multicolumn{2}{|c|}{ S.D. dependent var } & 137868.4422 \\
\hline S.E. of regressic & 137269.658 & \multicolumn{2}{|c|}{ Akaike info criterion } & 26.50165471 \\
\hline Sum squared re & $2.1406 \mathrm{E}+13$ & \multicolumn{2}{|c|}{ Schwarz criterion } & 26.52373912 \\
\hline Log likelihood & -15114.194 & \multicolumn{2}{|c|}{ Hannan-Quinn criter. } & 26.50999442 \\
\hline Durbin-Watson & 1.73413953 & & & \\
\hline
\end{tabular}

Dependent Variable: TRANS

Method: Least Squares

Date: 09/08/14 Time: 14:41

Sample: 11141

Included observations: 1141

White heteroskedasticity-consistent standard errors \& covariance

Variable Coefficient Std. Error t-Statistic Prob.

\begin{tabular}{|l|r|l|l|r|}
\hline HOGINI & 72381.555 & 15672.0985 & 4.618497962 & 0.0000 \\
\hline HOGEXP & 96101.4978 & 17219.5813 & 5.580942772 & 0.0000 \\
\hline HOGCON & 82005.8797 & 9968.88893 & 8.226180504 & 0.0000 \\
\hline PAREJOV & 70330.8248 & 23202.5472 & 3.031168273 & 0.0025 \\
\hline PARMAY & 67878.7188 & 14517.5421 & 4.675634375 & 0.0000 \\
\hline R-squared & 0.09308881 & Mean dependent var & 60875.52988 \\
\hline $\begin{array}{l}\text { Adjusted R-squ } \\
\text { S.E. of regressic }\end{array}$ & 0.08286279 & S.D. dependent var & 142912.4456 \\
\hline Sum squared re & 2.35 E +13 & Schwarz criterion & 26.61708963 \\
\hline Log likelihood & -15167.4505 & Hannan-Quinn criter. & 26.60334493 \\
\hline Durbin-Watson & 1.71200142 & & & \\
\hline
\end{tabular}


Composición de los hogares y niveles de gastos en bienes y servicios básicos en el Departamento del Cauca, Colombia

\section{Anexo 4. Estimaciones Gastos en bienes y servicios. Cauca Urbano. Ciclo de Vida (Continuación)}

\begin{tabular}{|c|c|c|c|c|}
\hline \multicolumn{5}{|c|}{ Dependent Variable: GASPER } \\
\hline \multicolumn{2}{|c|}{ Method: Least Squares } & & & \\
\hline \multicolumn{5}{|c|}{ Date: 09/08/14 Time: $14: 40$} \\
\hline \multicolumn{2}{|c|}{ Sample: 11141} & & & \\
\hline \multicolumn{3}{|c|}{ Included observations: 1141} & & \\
\hline \multicolumn{5}{|c|}{ White heteroskedasticity-consistent standard errors \& covariance } \\
\hline Variable & Coefficient & Std. Error & t-Statistic & Prob. \\
\hline HOGINI & 60352.2382 & 8306.93807 & 7.26528087 & 0.00 \\
\hline HOGEXP & 88468.1334 & 16622.6147 & 5.322155096 & 0.00 \\
\hline HOGCON & 91652.5209 & 9696.4673 & 9.452155925 & 0.00 \\
\hline PAREJOV & 95508.4293 & 25740.0559 & 3.710498137 & 0.00 \\
\hline PARMAY & 53082.6088 & 7433.74885 & 7.140758965 & 0.00 \\
\hline R-squared & 0.1103575 & \multicolumn{2}{|c|}{ Mean dependent var } & 72154.8477 \\
\hline Adjusted R-s & 0.10426721 & \multicolumn{2}{|c|}{ S.D. dependent var } & 128760.516 \\
\hline S.E. of regres & ؟ 135918.128 & \multicolumn{2}{|c|}{ Akaike info criterion } & 26.4818655 \\
\hline Sum squarec & $2.0986 \mathrm{E}+13$ & \multicolumn{2}{|c|}{ Schwarz criterion } & 26.5039499 \\
\hline Log likelihoo & -15102.9043 & \multicolumn{2}{|c|}{ Hannan-Quinn criter. } & 26.4902052 \\
\hline Durbin-Wats & 1.40237493 & & & \\
\hline
\end{tabular}

\begin{tabular}{|c|c|c|c|c|}
\hline \multicolumn{3}{|c|}{ Dependent Variable: AHORRO } & & \\
\hline \multicolumn{2}{|c|}{ Method: Least Squares } & & & \\
\hline \multicolumn{5}{|c|}{ Date: 09/08/14 Time: $14: 40$} \\
\hline \multicolumn{5}{|c|}{ Sample: 11141} \\
\hline \multicolumn{5}{|c|}{ Included observations: 1141} \\
\hline \multicolumn{5}{|c|}{ White heteroskedasticity-consistent standard errors \& covariance } \\
\hline Variable & Coefficient & Std. Error & t-Statistic & Prob. \\
\hline HOGINI & 19240.7045 & 11201.4626 & 1.71769572 & 0.08612 \\
\hline HOGEXP & 12326.0986 & 10677.9537 & 1.15435025 & 0.24860 \\
\hline HOGCON & 67150.7256 & 58267.244 & 1.15246099 & 0.24937 \\
\hline PAREJOV & 8482.19178 & 4365.14239 & 1.94316497 & 0.05224 \\
\hline PARMAY & 73182.9374 & 72520.8116 & 1.00913015 & 0.31313 \\
\hline R-squared & 0.00252223 & \multicolumn{2}{|c|}{ Mean dependent var } & 36046.9954 \\
\hline Adjusted R-squa & 0.00237424 & \multicolumn{2}{|c|}{ S.D. dependent var } & 550235.652 \\
\hline S.E. of regressio & 551273.035 & \multicolumn{2}{|c|}{ Akaike info criterion } & 29.2822205 \\
\hline Sum squared re: & $3.4523 E+14$ & \multicolumn{2}{|c|}{ Schwarz criterion } & 29.3043049 \\
\hline Log likelihood & -16700.5068 & \multicolumn{2}{|c|}{ Hannan-Quinn criter. } & 29.2905602 \\
\hline Durbin-Watson: & 2.0023791 & & & \\
\hline
\end{tabular}

\begin{tabular}{|c|c|c|c|c|}
\hline \multicolumn{3}{|c|}{ Dependent Variable: VEST } & & \\
\hline \multicolumn{2}{|c|}{ Method: Least Squares } & & & \\
\hline \multicolumn{3}{|c|}{ Date: 09/08/14 Time: $14: 41$} & & \\
\hline \multicolumn{2}{|c|}{ Sample: 11141} & & & \\
\hline \multicolumn{3}{|c|}{ Included observations: 1141} & & \\
\hline \multicolumn{5}{|c|}{ White heteroskedasticity-consistent standard errors \& covariance } \\
\hline Variable & Coefficient & Std. Error & t-Statistic & Prob. \\
\hline HOGINI & 42028.3628 & 6223.78488 & 6.752862381 & 0.0000 \\
\hline HOGEXP & 56235.9307 & 11053.6555 & 5.08754145 & 0.0000 \\
\hline HOGCON & 40005.8923 & 5337.67257 & 7.495006807 & 0.0000 \\
\hline PAREJOV & 50906.6667 & 15342.4977 & 3.318016902 & 0.0009 \\
\hline PARMAY & 26481.0127 & 6182.40291 & 4.283288074 & 0.0000 \\
\hline R-squared & 0.06203269 & \multicolumn{2}{|c|}{ Mean dependent var } & 39256.9407 \\
\hline Adjusted R-s & 0.05577224 & \multicolumn{2}{|c|}{ S.D. dependent var } & 90144.0126 \\
\hline S.E. of regres & 93061.2942 & \multicolumn{2}{|c|}{ Akaike info criterion } & 25.7242768 \\
\hline Sum squarec & $9.8382 \mathrm{E}+12$ & \multicolumn{2}{|c|}{ Schwarz criterion } & 25.7463612 \\
\hline Log likelihoo & -14670.6999 & \multicolumn{2}{|c|}{ Hannan-Quinn criter. } & 25.7326165 \\
\hline Durbin-Wats & 1.67915592 & & & \\
\hline
\end{tabular}

\begin{tabular}{|c|c|c|c|c|}
\hline \multicolumn{5}{|c|}{ Dependent Variable: VIV } \\
\hline \multicolumn{5}{|c|}{ Method: Least Squares } \\
\hline \multicolumn{5}{|c|}{ Date: 09/08/14 Time: $14: 41$} \\
\hline \multicolumn{5}{|l|}{ Sample: 11141} \\
\hline \multicolumn{5}{|c|}{ Included observations: 1141} \\
\hline \multicolumn{5}{|c|}{ White heteroskedasticity-consistent standard errors \& covariance } \\
\hline Variable & Coefficient & Std. Error & t-Statistic & Prob. \\
\hline HOGINI & 261045.729 & 26508.5704 & 9.84759739 & 0.0000 \\
\hline HOGEXP & 280472.245 & 28548.5705 & 9.82438841 & 0.0000 \\
\hline HOGCON & 293801.698 & 22662.935 & 12.9639739 & 0.0000 \\
\hline PAREJOV & 342640.741 & 63197.5628 & 5.42173979 & 0.0000 \\
\hline PARMAY & 214656.413 & 30436.8735 & 7.05251189 & 0.0000 \\
\hline R-squared & 0.024296 & \multicolumn{2}{|c|}{ Mean dependent var } & 249355.371 \\
\hline Adjusted R-squé & 0.02173366 & \multicolumn{2}{|c|}{ S.D. dependent var } & 301317.522 \\
\hline S.E. of regressio & 336524.14 & \multicolumn{2}{|c|}{ Akaike info criterion } & 28.2950999 \\
\hline Sum squared re: & $1.2865 E+14$ & \multicolumn{2}{|c|}{ Schwarz criterion } & 28.3171843 \\
\hline Log likelihood & -16137.3545 & \multicolumn{2}{|c|}{ Hannan-Quinn criter. } & 28.3034396 \\
\hline Durbin-Watson: & 1.22440011 & & & \\
\hline
\end{tabular}

Fuente: elaboración propia 